\title{
La « Douceur » autrichienne contre la superbe des Bourbons : un éloge funèbre en images à la gloire de l'empereur Léopold I ${ }^{\text {er }}$ (Vienne, 1705)
}

\section{Philippine Dauga-Casarotto}

\section{(2) OpenEdition \\ Journals}

Édition électronique

URL : http://journals.openedition.org/rhetorique/689

DOI : $10.4000 /$ rhetorique.689

ISSN : 2270-6909

Éditeur

UGA Éditions/Université Grenoble Alpes

Édition imprimée

ISBN : 978-2-37747-062-4

Référence électronique

Philippine Dauga-Casarotto, «La « Douceur » autrichienne contre la superbe des Bourbons : un éloge funèbre en images à la gloire de l'empereur Léopold ler (Vienne, 1705) », Exercices de rhétorique [En ligne], 11 | 2018, mis en ligne le 10 octobre 2018, consulté le 12 septembre 2020. URL : http:// journals.openedition.org/rhetorique/689; DOI : https://doi.org/10.4000/rhetorique.689

Ce document a été généré automatiquement le 12 septembre 2020.

\section{cc) (i) (2)}

Les contenus de la revue Exercices de rhétorique sont mis à disposition selon les termes de la Licence Creative Commons Attribution - Pas d'Utilisation Commerciale - Partage dans les Mêmes Conditions 4.0 International. 
La « Douceur » autrichienne contre la superbe des Bourbons : un éloge funèbre en images à la gloire de l'empereur Léopold I ${ }^{\text {er }}$ (Vienne, 1705)

Philippine Dauga-Casarotto

Innsbruck, 12 décembre 1740. Le conseil de Haute-Autriche célèbre les obsèques de l'empereur Charles VI, mort le 20 octobre précédent. Au milieu de l'église des jésuites trône un imposant catafalque éphémère, richement orné, destiné à accueillir le cercueil impérial pour le rituel de l'absoute (« absolutio ad tumulum »). 


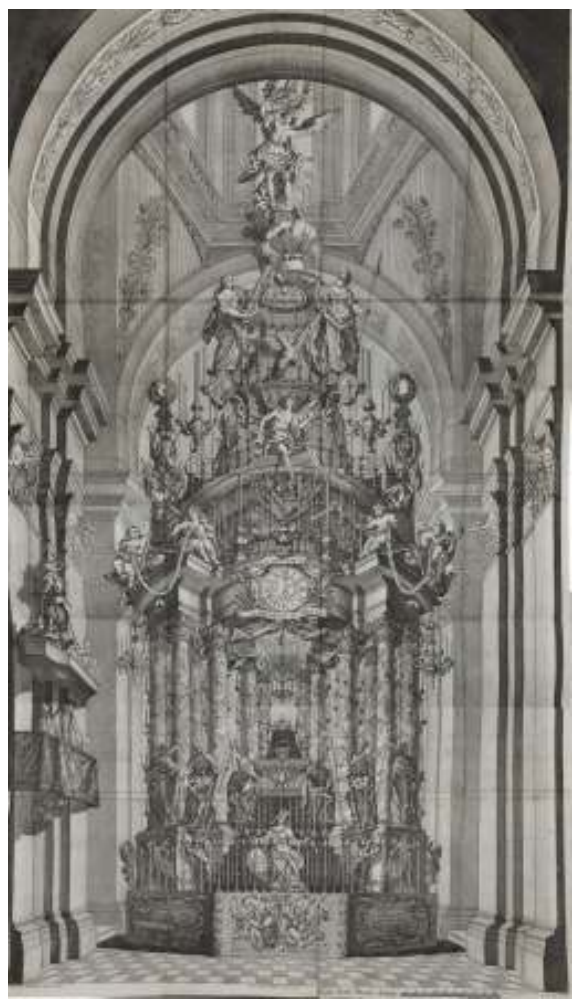

ILLUSTRATION 1

Castrum doloris érigé à Innsbruck dans l'église des Jésuites (église de l'Université) par Georg Anton Gumpp, architecte de la cour, à l'occasion des obsèques en l'honneur de Charles VI (12-14 décembre 1740) (c) Stiftsbibliothek Klosterneuburg [BK III 19/ 22, p. 351].

Cette ultime bénédiction qui clôt les funérailles a lieu à la fin des obsèques, en présence d'un cercueil vide, le cadavre du défunt empereur ayant été enterré quelques jours après son décès dans la Crypte des Capucins, à Vienne. Incarnation du goût baroque pour l'éphémère, le castrum doloris, qui rappelle les décors de théâtre ou les arcs de triomphe célébrant l'entrée du prince dans une ville, demeure sur place quelques jours, voire quelques semaines pour être admiré, puis il est détruit ou réutilisé pour d'autres cérémonies funèbres. Le présent édifice, conçu par Georg Anton Gumpp (1670/1682 vers $1730^{1}$ ) à la demande du Conseil de Haute-Autriche, a déjà servi en 1720, lors des funérailles de l'épouse du défunt, Eleonora Magdalena Theresia ${ }^{2}$. Gumpp a conservé la structure du castrum doloris de 1720, renouvelant seulement l'ornementation (inscriptions, scènes de la vie de l'empereur, emblèmes ornant l'église ${ }^{3}$ ).

"CEuvre d'art totale ${ }^{4}$ ", la pompe funèbre baroque sollicite tous les sens : l'ouïe (volées de cloches, musique funèbre, écoute de l'oraison funèbre), l'odorat (encens, odeur des cierges), le toucher (ornements liturgiques et vêtements de deuil prescrits par la liturgie et le cérémonial de Cour), et surtout la vue, mise au service de la «propagatio fidei » dans l'architecture, la peinture et la sculpture post-tridentines ${ }^{5}$. En de vibrantes hypotyposes, les relations d'obsèques et les oraisons funèbres dépeignent les sensations qui submergent quiconque assiste à la célébration des obsèques impériales, qu'il soit noble ou homme du peuple. À grand renfort d'antithèses pleines de pathos, elles soulignent le contraste entre le noir omniprésent (dais surmontant le catafalque, tentures sur le cercueil et les murs des églises, ornements liturgiques, tenue des courtisans et livrée des serviteurs, jusqu'aux fourreaux des épées et aux boutons des 
habits $\left.{ }^{6}\right)$ et l'éclat des cierges illuminant l'appareil funèbre durant les trois messes de requiem célébrées pendant trois jours consécutifs.

Souvent, les gravures de catafalques éphémères inscrivent le monument dans son cadre, pour mieux en faire ressortir les dimensions imposantes : on entr'aperçoit les colonnes de l'église, la clef de voûte, le dallage du sol, parfois même une assistance admirative. Détail suffisamment rare pour être souligné, le lien entre éloquence et architecture funèbre est clairement établi dans la gravure immortalisant le catafalque éphémère évoqué précédemment (illustration 1). Le Tyrolien Franz Michael Hueber (? - 1746), peintre à la cour d'Innsbruck, spécialisé dans les fresques et les décorations ${ }^{7}$, a représenté le prédicateur prononçant l'oraison funèbre du haut de la chaire tendue de velours noir, comme il se doit en pareille occasion. Outre les impératifs acoustiques, la position surélevée de la chaire, surmontée d'une voûte, symbole de majesté, rend visible l'autorité de la parole du prédicateur. Ici comme sur les fresques d'églises, de monastères ou de palais, le goût baroque affectionne l'illusion : peinture, sculpture et architecture se jouent des frontières entre réel et représentation. L'orateur, en pleine actio, est figé dans une gestuelle qui rappelle les croquis illustrant la rhétorique du corps dans les manuels d'éloquence et de prédication. Il semble apostropher une statue du castrum doloris, qui paraît presque vivante; celle-ci représente un chef militaire en armure couronné de lauriers, portant le collier de la Toison d'Or. Tournant le dos à un squelette, ce chef militaire, en appui sur une jambe, une main sur la hanche, lève un visage attentif vers le prédicateur. Sous ses pieds, sur le socle de l'édifice, on aperçoit une vue de Barcelone, allusion à la conquête de cette ville en 1705, pendant la guerre de Succession d'Espagne. L'inscription sur le castrum doloris impute cette victoire à Léopold $\mathrm{I}^{\mathrm{er}}:$ «Barcelone, courageusement conquise par Léopold le Grand ${ }^{8}$ ». Bien qu'il n'arbore aucun insigne impérial, ce chef en armure pourrait donc représenter Léopold I ${ }^{\text {erg }}$. Par un artifice qui brouille les repères spatiaux-temporels, ce détail de la gravure mettrait donc en scène l'empereur Léopold $\mathrm{I}^{\mathrm{er}}$ écoutant l'éloge funèbre de son fils Charles VI. La représentation des ancêtres est un topos important dans la décoration funèbre. Elle permet de souligner la continuité du pouvoir et d'exalter la longévité " providentielle» de la dynastie. Le castrum doloris devient ainsi une sorte de panthéon de la dynastie habsbourgeoise, où les ancêtres immortels veillent sur leurs descendants, auxquels ils ont transmis leurs vertus « héréditaires ".

Ce dialogue entre un orateur et une statue d'empereur renvoie par ailleurs au topos de la concurrence entre les arts. Architecture et éloquence funèbres rivalisent d'ingéniosité dans l'éloge de l'empereur. C'est cette même correspondance que nous allons retrouver à l'œuvre dans la pompe funèbre célébrée en 1705 par les jésuites de la Maison Professe de Vienne, en l'honneur de l'empereur Léopold $\mathrm{I}^{\mathrm{er}}$. Une présentation du rituel des obsèques impériales permettra de situer cette cérémonie de 1705 dans un cadre plus vaste. Nous mettrons en évidence son contexte en analysant de façon détaillée le titre de l'oraison funèbre, révélateur du rapport existant entre les jésuites et la dynastie habsbourgeoise. L'oraison funèbre prononcée par le jésuite Thomas Winter sera ensuite considérée dans ses rapports avec l'appareil funèbre. On se demandera enfin quelle représentation princière ce discours en images tend à élaborer, et quel arrière-plan intellectuel nourrit la prédication. 


\section{Pompe funèbre, mémoire et représentation impériale dans les pays de la Maison d'Autriche, du XVI au XVIII siècle}

$5 \mathrm{Au} \mathrm{XVI}{ }^{e}$ siècle, la dimension politique des funérailles impériales se manifeste dans les cérémonies, les œuvres de circonstance (poèmes, discours) et les représentations graphiques qui entourèrent la mort de Maximilien I ${ }^{\mathrm{er}}(\dagger$ 1519), de Charles Quint ( $†$ 1558) et de Ferdinand $\mathrm{I}^{\mathrm{er}}(\dagger 1565)$. Ces princes connaissaient l'importance de la représentation et de la mémoire. La dynastie habsbourgeoise était à la tête de l'Empire et des possessions danubiennes depuis l'élection d'Albert II en 1438. Pour compenser le caractère électif, et par conséquent incertain, de la dignité impériale, la Maison d'Autriche cultivait une apparence de stabilité inébranlable, comme si sa domination ne dût jamais s'arrêter. Le convoi funèbre incarnait la puissance, la structure hiérarchique et l'extension géographique de la Monarchie habsbourgeoise : on y voyait défiler dans un ordre bien précis les différentes institutions et les hérauts de toutes les provinces ${ }^{10}$. Le concile de Trente (1545-1563) réaffirma, contre l'acception protestante de l'Eucharistie, la valeur propitiatoire de la messe et l'intercession des vivants pour les morts. Les messes célébrées à la mémoire des empereurs défunts s'entourèrent d'un faste grandissant.

6 La mode italienne des catafalques monumentaux pénétra l'espace danubien dans le courant du XVII ${ }^{\mathrm{e}}$ siècle. À la mort du roi Ferdinand IV († 1654), le catafalque supplanta le convoi funèbre au cœur de la cérémonie funèbre. Comme cette construction éphémère exigeait de longs préparatifs, on prit l'habitude d'inhumer le défunt empereur trois jours après sa mort, sans trop de faste, et de célébrer des obsèques solennelles un, deux voire trois mois après. Non seulement dans la capitale viennoise, mais dans de nombreuses villes, les différents corps de la Monarchie (gouvernements de province, municipalités, universités, ordres religieux) voulurent témoigner leur soumission à la dynastie par des funérailles de plus en plus solennelles, en faisant construire à grand frais un castrum doloris qui supportait un cercueil vide. La conception, la réalisation, la décoration (tentures, trophées, symboles macabres, sculptures, stucs, peintures, dorures, effets spéciaux) puis la représentation gravée du castrum doloris et sa diffusion représentaient un coût très élevé, sans compter le prix des cierges, matière rare et chère, qui se consumaient par centaines, voire par milliers ${ }^{11}$.

\section{Les cérémonies extraordinaires de la Compagnie de Jésus : les funérailles impériales organisées par le Collège et la Maison Professe de Vienne en 1705}

7 Les jésuites s'étaient établis à Vienne en 1551, à la demande de l'empereur Ferdinand $\mathrm{I}^{\text {er12}}$. La Compagnie, jouissant de la protection de Ferdinand II, Ferdinand III et Léopold $\mathrm{I}^{\text {er }}$, n'avait cessé d'étendre son réseau de collèges et d'universités, qui couvrait tous les territoires de la Monarchie, assurant l'éducation et la formation des élites. En 1623, suite à une décision de l'empereur Ferdinand II, le Collège de Vienne fut partiellement intégré à l'Université ${ }^{13}$, sur laquelle les jésuites exercèrent une influence prépondérante jusqu'à la mort de Léopold I ${ }^{\text {er }}$ en 1705. En 1624, Ferdinand II posa la première pierre de l'église des jésuites de Vienne (actuelle "Universitätskirche»), au 
cœur d'un quartier universitaire entièrement rénové. En 1631 eut lieu la consécration en présence de l'empereur et de toute la cour ${ }^{14}$. C'est en Léopold $\mathrm{I}^{\mathrm{er}}$ que la Compagnie de Jésus connut son plus grand bienfaiteur. Selon la maxime «do, ut des ", " honorer pour être honoré15 », les jésuites de Vienne mirent, à la mort de ce dernier en 1705, un point d'honneur à manifester leur reconnaissance par de «justes louanges»; il s'agissait également d'inciter Joseph I ${ }^{\text {er }}$, le successeur au trône, à faire preuve, à l'égard de la Compagnie, de la même bienveillance que son père :

À toutes ces cérémonies, il convenait que le Collège académique de la Compagnie de Jésus vînt prendre sa part, étant attaché depuis longtemps déjà à toute l'auguste famille des empereurs d'Autriche ; et étant présentement attaché au grand Léopold de glorieuse mémoire, pour des raisons si importantes que le Collège ne pourra jamais s'acquitter dûment de sa dette, quels que soient les moyens mis en œuvre ${ }^{16}$.

En vertu de cette "dette infinie envers l'Archi-Maison en général, et envers le Très Puissant et Très Glorieux Empereur Léopold en particulier ", le Collège décide donc "d'exposer aux yeux du monde un monument exprimant sa reconnaissance très soumise envers cet immortel prince des vertus, mort dans la béatitude " et "d'employer toutes ses forces pour rendre à celui-ci tous les honneurs possibles, dussent-ils demeurer toujours insuffisants ${ }^{17}{ }^{1}$. Ces cérémonies eurent lieu du 19 au 21 août 1705.

Du 25 au 27 juin 1705, le second établissement jésuite de Vienne, la Maison Professe, vouée à des œuvres de pastorale et de bienfaisance, avait déjà organisé sa propre cérémonie d'obsèques dans son église "Am Hof" (actuelle église des Neuf Chœurs angéliques). Cette démultiplication des funérailles impériales, qui perdure pendant tout le XVIII ${ }^{\mathrm{e}}$ siècle, montre l'importance accrue de ces commémorations qui associent les sujets et tout le corps social à la création d'une mémoire dynastique. La Maison Professe ne ménagea pas ses efforts, puisqu'elle fit réaliser un castrum doloris destiné à être illuminé pendant chacune des trois messes de requiem, comme le voulait la tradition. L'édifice ${ }^{18}$ (illustration 2) se présente comme un temple de structure cubique percée de trois travées, imitant une grotte ornée de coquillages. Il repose sur un podium décoré de représentations de villes et de pays de la Monarchie; deux phénix sortant des flammes y sont perchés. Sur les piliers soutenant les arcades, deux figures féminines présentent le sceptre et le glaive, attributs du pouvoir. Elles sont surmontées par deux séries d'aigles bicéphales; un autre aigle est perché sur les marches du podium, un autre encore tient dans son bec la couronne impériale qui chapeaute l'ensemble, et d'où s'échappent les quatre pans d'un dais de velours noir maintenu par des angelots. L'aigle est un motif omniprésent dans la décoration funèbre. Emblème impérial par excellence, allégorie des vertus princières, il sert également de thème à de nombreuses oraisons funèbres. Le centre du castrum doloris est occupé par le cercueil veillé par l'aigle impérial et le lion de Bohême. 


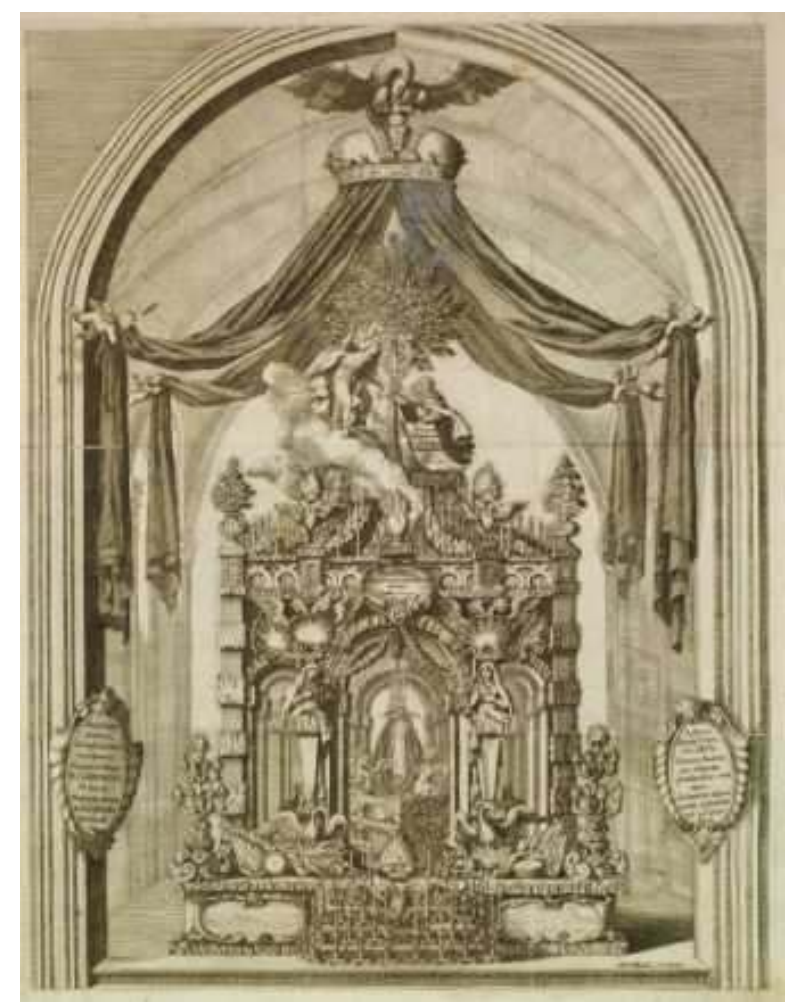

\section{ILLUSTRATION 2}

Castrum doloris érigé en l'église «Am Hof» (actuelle église des Neuf Chœurs angéliques, Vienne), lors des obsèques organisées par la Maison professe de la Compagnie de Jésus en l'honneur de Léopold ler, du 25 au 27 juin 1705. (c) Österreichische Nationalbibliothek [569.096.B].

Le goût baroque veut que chaque catafalque développe un thème précis sur un mode allégorique ${ }^{19}$. Ici, l'« argumentum » se déploie sur la partie supérieure de l'édifice. Sur un nuage de fumée s'échappant d'un cœur enflammé se déroule une scène à deux personnages. Agenouillé sous un olivier, l'empereur Léopold I ${ }^{\text {er }}$ est hissé vers l'immortalité par une figure féminine qui porte sur sa tête une colombe, symbole de douceur et de paix : il s'agit d'une personnification de la mansuétude. L'empereur tient un rouleau portant un verset du Psaume 131 (v. 1) : «Souviens-toi, Seigneur, de David et de toute sa douceur ${ }^{20}$ ». La "douceur» ("Sanfftmuth») de Léopold $\mathrm{I}^{\mathrm{er}}$ constitue également le thème de la longue oraison funèbre (79 pages) conçue par le jésuite Thomas Winter. Elle fut prononcée en trois jours, après chaque messe de "requiem ", sous le titre :

Éloge de la douceur trois fois bienheureuse de sa Majesté romaine impériale Léopold Ir le Grand, roi de Hongrie et de Bohême etc., de bienheureuse et glorieuse mémoire ; à l'occasion des obsèques célébrées trois jours consécutifs dans l'église de la maison professe impériale de la Compagnie de Jésus; pour lui rendre de justes honneurs, dans un sermon de louange et de consolation divisé en trois parties, suivant le remarquable mausolée érigé en l'honneur de la douceur trois fois bienheureuse, abondamment éclairé, par Thomas Winter, prêtre de la Compagnie de Jésus, prédicateur ordinaire dans ladite église le dimanche et pendant le carême ${ }^{21}$.

\section{Le « decorum » dans le titre de l'oraison funèbre}

Ce titre fait apparaître le cadre cérémoniel qui conditionne le discours. L'oraison funèbre se rattache à la rhétorique d'apparat («Prunkrhetorik») ou rhétorique de Cour 
("höfische Rhetorik»), qui regroupe toutes les formes de discours pratiquées dans le cadre des gouvernements monarchiques et des cultures de cour ${ }^{22}$. Aux yeux de Pierre Zoberman, « les structures sociales du Grand Siècle constituent un contexte propice à l'activité oratoire "; " les cérémonies publiques contribuent à la culture de la parole ${ }^{23}$ ». Michèle Fogel définit le cérémonial comme «organisation étatique de pratiques sociales ». La cérémonie est un « ensemble articulé d'éléments rituels qui fixent au plus près, par les objets, les gestes et les paroles, la place qui revient à chacun dans la hiérarchie des pouvoirs ${ }^{24} »$. Par les nombreux détails qu'il mentionne, le titre exprime la fonction sociale et politique de l'oraison funèbre. Il récapitule les conditions d'énonciation auxquelles l'orateur, selon Quintilien, doit être attentif lorsqu'il compose son discours :

L'orateur doit considérer ce qu'il a à dire, devant qui, pour qui, contre qui, à quel moment, en quel lieu, dans quelle conjecture, ce qu'on dit dans le public [devant quelle opinion publique ${ }^{25}$ ?

La mention du castrum doloris, point culminant de la pompe funèbre et attraction majeure, contribue à la « solennisation » du discours ${ }^{26}$ et met en valeur la libéralité du commanditaire, la Maison professe : cela correspond à la stratégie des jésuites visant à conserver la faveur princière, un enjeu véritablement existentiel pour chaque individu et chaque institution, dans cette société très hiérarchisée. C'est aussi pour cette raison que l'oraison funèbre et la description de la décoration sont fréquemment dédiées au successeur au trône. L'expression "Maison professe impériale » exprime avec force le lien qui unit les jésuites aux Habsbourg - le Collège jésuite de Vienne se qualifie également d'« impérial».

En participant à l'œuvre de reconquête religieuse contre le protestantisme, les jésuites prêtent assistance à l'empereur dans sa mission "apostolique ", et contribuent à fortifier les fondements transcendants du pouvoir politique. En retour, l'empereur comble de sa "grâce " les instruments de sa politique. En rendant à Léopold I ${ }^{\text {er }}$ les honneurs funèbres, la Maison professe des jésuites s'acquitte de sa « dette » vis-à-vis de l'empereur et de la dynastie. Tel est le sens, dans le titre, de l'expression "pour lui rendre de justes honneurs ", qui inscrit le discours et la cérémonie des funérailles dans l'économie du respect, de l'honneur et de la gratitude ${ }^{27}$ sur laquelle reposent la société et le pouvoir de la Monarchie.

12 L'impératif de bienséance (" decorum », "Angemessenheit ») gouverne le discours : il doit y avoir harmonie entre la personne de l'orateur (âge, qualité, position sociale), l'objet dont il traite, le public, les circonstances (temps et lieu) et enfin le style du discours ${ }^{28}$. L'importance de la bienséance dans la société d'Ancien Régime est manifestée par l'abondance, dans les oraisons funèbres, des créations lexicales qui combinent des notions comme le devoir («Pflicht»), la dette («Schuld»), l'obligation («Verbundenheit $»)$, la gratitude («Danck»), l'équité («Billigkeit»), l'amour («Liebe»), l'humilité (" Demut»), la mémoire ("Andenken»), la sujétion ("Unterthänigkeit»). Ainsi notre prédicateur fait-il allusion, dans son exorde, au castrum doloris érigé «dans une gratitude reconnaissante et très obligée ${ }^{29}$ ".

Dans le titre de son oraison funèbre, Thomas Winter utilise, comme il se doit, la petite titulature de Léopold I ${ }^{\text {er }}$, qui ne mentionne que l'Empire et les royaumes de Bohême et de Hongrie. Les quelques soixante autres titres sont suggérés par un elliptique "etc. ", allusion à la grande titulature. De 1440 à 1806 , à une brève interruption près ${ }^{30}$, les Habsbourg conservèrent la dignité impériale, la plus prestigieuse après le titre 
pontifical. Dignité fragile néanmoins, car élective et par conséquent soumise au bon vouloir du collège des princes-électeurs et aux fluctuations de la politique allemande et internationale. Insister sur les titres, les symboles et le cérémonial, c'était donner l'impression que le règne des Habsbourg, cautionné par la Providence, avait vocation à se poursuivre éternellement. Toujours et partout, il fallait que ces titres et symboles fussent visibles, il fallait démontrer avec ostentation l'illustre longévité de la dynastie habsbourgeoise, dont la domination devait se présenter comme évidente et inébranlable aux yeux de tous les sujets: fresques ornant les plafonds des abbayes, inscriptions au fronton des églises, blasons omniprésents, rituels entourant toute apparition publique du monarque, etc.

L'oraison funèbre de Thomas Winter exalte dans son titre la douceur de «Léopold le Grand ». Par analogie avec Louis XIV, son ennemi et rival dans l'Empire et en Espagne, Léopold $\mathrm{I}^{\text {er }}$ fut en effet, de son vivant, appelé "Le Grand». De nombreuses oraisons funèbres sont centrées sur la justification de ce prédicat.

\section{Architecture et éloquence funèbres au service de l'éloge de l'empereur}

\section{L'oraison funèbre, un genre hybride}

15 En allemand, une multitude de noms désignent l'oraison funèbre. Les titres des oraisons funèbres utilisent tantôt le terme " discours » (" oratio funebris », "Leichenrede »), tantôt celui de sermon (" concio funebris», «Leichenpredigt »). On perçoit la double filiation du genre, issu d'une symbiose entre la rhétorique païenne et la prédication chrétienne. L'emploi quasi indifférencié du terme "Predigt» et du terme «Rede» reflète le caractère hybride du genre. Le jésuite romain Charles Regius (Carlo Reggio) qualifie l'oraison funèbre de "genus mixtum», "genre hybride ${ }^{31}$ ». Le discours de Thomas Winter s'intitule "Predigt», et effectivement il tient davantage de l'homélie que de la "laudatio funebris", puisqu'il s'appuie sur un thème biblique, et puise l'essentiel de ses arguments dans les Écritures.

Dans le contexte des funérailles catholiques, l'oraison funèbre assume - non sans tiraillements - plusieurs fonctions. Lamentation ("lamentatio», « Trauer») et éloge (" laudatio ", "Lob») sont un héritage à la fois vétéro-testamentaire et païen. La consolation (" consolatio », "Trost»), l'instruction (« instructio ») et l'appel à l'imitation du défunt ("aemulatio ») sont plus nettement inspirées par la prédication patristique et ont pour but l'édification des fidèles. La lamentation et l'éloge tendent vers la création d'une mémoire collective; ils visent à renforcer les liens affectifs entre le défunt souverain et ses sujets, à écrire l'histoire de la " gloire » du prince. L'équilibre entre ces deux aspects est délicat, comme on l'a constaté à propos de Bossuet ${ }^{32}$. En 1740, à Bozen/ Bolzano, un chanoine prononce en l'honneur de l'empereur Charles VI une oraison funèbre dont le titre ("Discours funèbre de louange, de consolation et d'édification ${ }^{33}$ ) traduit l'oscillation du genre entre le profane et le sacré.

Dans son titre, Thomas Winter annonce un «sermon de louange et de consolation " (« Lob- und Trost-Predige »). Il justifie dans l'exorde son refus de la lamentation, en arguant, à grand renfort de citations et d'amplifications, qu'il ne sied pas, pour les chrétiens, de pousser des soupirs et de porter le deuil d'un empereur qui a, selon toute probabilité, gagné la lumière éternelle, dont les cierges sont le symbole ${ }^{34}$. Le prédicateur surprend 
son auditoire en ébranlant l'interprétation traditionnelle des symboles de la décoration funèbre. Les tentures et vêtements noirs, explique-t-il, ne servent en aucun cas à exprimer une "douleur intérieure ", mais uniquement à montrer que l'on observe les prescriptions vestimentaires en vigueur à la cour, pendant le «grand deuil» («Große Hoff- und Landt-Klage ») décrété à la mort d'un empereur. On ne saurait exprimer plus clairement qu'en ce qui concerne le cérémonial de cour, la forme est plus importante que la sincérité des sentiments: "Il s'agit [...] presque uniquement de paraître en arborant comme tout le monde la couleur du deuil prescrite en ces circonstances à la cour, et d'être vu dans cette tenue ${ }^{35}$.» Cependant, l'intention de Winter n'est pas de fustiger l'hypocrisie des courtisans ou de remettre en question l'étiquette, mais de redonner un sens chrétien à des pratiques de deuil issues de l'Antiquité païenne. Il s'appuie sur une affirmation de saint Cyprien selon laquelle il n'est pas approprié de porter des vêtements noirs en l'honneur d'un défunt qui a déjà revêtu les vêtements blancs de l'immortalité. Le refus de la "lamentatio ", topos fréquent dans les oraisons funèbres, sert également de transition vers la «laudatio ».

\section{Architecture parlante et monument de papier : la mise en scène allégorique de la Douceur couronnant l'empereur}

En cette année 1705, en pleine lutte pour la couronne d'Espagne, l'empereur Léopold I ${ }^{\text {er }}$ s'éteint après un règne de 47 ans. Dans la capitale viennoise, qu'un confrère de Thomas Winter nommait la «demeure originelle des aigles romains ${ }^{36}$ ", de nombreuses institutions (municipalité, ordres religieux, confréries) rivalisent de zèle et d'ingéniosité pour mettre en paroles et en images près d'un demi-siècle d'histoire dynastique : pour la seule ville de Vienne, on dénombre, outre l'appareil commandé par la Maison professe, cinq catafalques éphémères érigés respectivement dans l'église Saint-Augustin ${ }^{37}$, dans l'église Saint-Michel (obsèques de la Confrérie Espagnole du Saint Sacrement) et dans l'église de l'Université (obsèques du Collège jésuite). Dans cette atmosphère d'émulation générale, Thomas Winter propose, pour un public avide de nouveauté, une oraison funèbre qui consiste de bout en bout, comme l'annonce le titre, en un commentaire du castrum doloris. Thomas Winter résume en ces mots l'argument de l'édifice funèbre:

Avant tout, le castrum doloris veut manifester au monde la Douceur divine ellemême; sous l'olivier - allusion à la mansuétude et à la miséricorde -, celle-ci, nimbée de nuages argentés, tend la main droite à la douce âme de Léopold; de l'autre, elle s'apprête à le couronner d'un rameau pris sur ce même olivier ${ }^{38}$.

Il ne fait aucun doute qu'ici, le prédicateur, Thomas Winter, est aussi l'inventeur de la décoration funèbre - comme ce fut le cas dans bien d'autres obsèques impériales $d u$ XVIII ${ }^{\mathrm{e}}$ siècle. En effet, aucune source n'évoque l'architecte ${ }^{39}$ : Winter aura sans doute souhaité, par modestie, que son nom ne soit pas mentionné sur la gravure et dans les relations d'obsèques.

19 L'analogie entre le discours et l'édifice ne s'arrête pas à cette thématique commune: tous deux se correspondent jusque dans les détails de leur structure. Le médaillon central du catafalque, que nous pouvons apercevoir au milieu de l'architrave, sur la seule face visible sur la gravure, porte l'inscription qui sert de thème à l'oraison funèbre: «Beati Mites; quoniam ipsi possidebunt Terram ${ }^{40}$ " (Mt. 5, 4). Thomas Winter propose une triple interprétation de cette béatitude : 1 . La douceur de Léopold a été récompensée par le succès de ses conquêtes. 2. Par elle, il a régné sur le cœur de ses 
sujets, dont il a su se faire aimer. 3. Enfin, la mansuétude impériale recevra en héritage la terre promise, métaphore de la vie éternelle. Ces trois acceptions du "possidebunt terram » fournissent à la fois la structure de l'oraison funèbre et celle du castrum doloris. Dans un souci didactique, cette "partitio " est expliquée dans l'exorde de l'oraison funèbre ${ }^{41}$, à grand renfort de citations de Pères et de Docteurs de l'Église (saint Jean Chrysostome, saint Jérôme, saint Bernard de Clairvaux), ainsi que d'exégètes contemporains (Cornelius a Lapide ${ }^{42}$, qui servira de fil rouge à la démonstration, tout au long du discours ; Thomas Cajetan ${ }^{43}$ ). Outre le thème biblique général tiré de l'Évangile selon Saint Matthieu, chacune des trois parties du discours est placée sous le signe d'une citation des Écritures qui figure également sur un médaillon du Temple de la Douceur. Ici encore, les repères spatio-temporels soulignent l'« occasio » du discours :

Première partie pour le premier jour du «triduum » funèbre: Première conquête de la douceur impériale de Léopold, pour l'agrandissement de son empire terrestre et de ses possessions. Contenu de l'écusson du milieu, du côté droit : « Mansueti autem haereditabunt terram ; \& delectabuntur in multitudine Pacis $^{44}$. » $(\text { Ps. 36, 11 })^{45}$

Deuxième partie pour le second jour des obsèques : seconde conquête de la douceur de Léopold dans la possession des cœurs humains. Contenu du médaillon central sur le côté opposé : "In Mansuetudine opera tua dirige; \&, super hominum gloriam, diligêris ${ }^{46}$. " $(\text { Eccl. 3, 19) })^{47}$

Troisième partie pour le troisième jour des obsèques; troisième conquête de la douceur de Léopold, à savoir l'entrée dans le paradis céleste. Contenu du médaillon central du côté du maître-autel: «Suspiciens Mansuetos Dominus: Humilians autem peccatores, usque ad Terram ${ }^{48}$. $\left(\right.$ Ps. 146, 6) ${ }^{49}$

L'idée de la béatitude est donc au centre du Temple de la Douceur de 1705, et la troisième partie de l'oraison funèbre de Thomas Winter, sommet de son argumentation, s'emploie à montrer que, selon toute probabilité, l'empereur est entré directement au paradis. Le salut de l'âme est une préoccupation centrale, surtout lorsque le défunt est un empereur. Plusieurs prédicateurs, en 1705, proclament - non sans susciter de polémiques - la « sainteté » de l'empereur ${ }^{50}$.

\section{Éloge, allégorie et emblématique dans les funérailles impériales : de subtiles relations entre discours et architecture funèbres}

Un demi-siècle auparavant, à la mort du roi Ferdinand IV († 1654) et à celle de son père, l'empereur Ferdinand III ( $† 1657)$, les confrères de Thomas Winter attachés au Collège jésuite de Vienne avaient déjà mis leur érudition biblique et antique au service de la glorification impériale. En 1654, lors des obsèques officielles en l'église Saint-Augustin, le décorateur de théâtre Giovanni Burnacini avait conçu un castrum doloris surmonté d'un phénix renaissant des cendres; le jésuite Thomas Dueller avait prêché sur le thème du "Phénix autrichien ${ }^{51}$ ", mais sans évoquer l'appareil funèbre ${ }^{52}$.

Trois ans plus tard, dans son oraison prononcée en l'honneur de Ferdinand III dans l'église des jésuites de Vienne (ou église de l'Université), son confrère Christopher Traut jongle avec plusieurs trames symboliques aussi riches que complexes, qui méritent d'être détaillées, car on en retrouve de nombreux échos dans le sermon qui nous occupe. Une double interprétation du symbole de l'aigle encadre et structure le discours. Dans l'exorde et le développement, Ferdinand III est comparé à l'aigle qui "prenait la sève des cèdres ", évoqué par le prophète Ézéchiel. La démonstration de la " pietas austriaca » constitue l'objectif de cette allégorie, qui signifie que Ferdinand III se nourrissait de l'Eucharistie, aliment suprême des empereurs ${ }^{53}$. Dans la péroraison, le 
prédicateur introduit la seconde dimension de la métaphore : l'aigle comme symbole de la Rome antique. Traut rapporte - non pas d'après Tacite et Suétone, mais d'après un ouvrage d'ornithologie ${ }^{54}$ - la pratique romaine de l'apothéose ou "consecratio", qui s'imposa sous Auguste: on érigeait un bûcher funèbre ("rogus funebris») décoré de trophées militaires et de peintures; sur un tapis écarlate, on plaçait au milieu le portrait de l'empereur; au sommet du bûcher, on attachait un aigle vivant qui s'envolait vers le séjour des dieux, lorsque les flammes avaient brûlé ses liens ${ }^{55}$. L'aigle incarne ici l'idée sans cesse réactivée de la "translatio imperii », qui signifiait le transfert de la dignité impériale de la Rome antique vers l'Allemagne et, de façon privilégiée, vers la dynastie habsbourgeoise. Reprenant le topos du dépassement de l'Antiquité " païenne et aveugle » par la civilisation chrétienne, Traut réinterprète chaque élément $\mathrm{du}$ « rogus funebris» dans un sens chrétien, car « seule la vraie religion de l'empereur chrétien et la vénération de l'unique vrai Dieu, peut rendre immortel ${ }^{56}$. " Selon Traut, c'est l'empereur Ferdinand III lui-même qui s'est élevé un monument à trois étages (représentant respectivement la dévotion envers les saints, envers la Vierge et envers Dieu). L'argent de l'affabilité, l'ivoire de la sagesse et l'or de la générosité illuminent l'édifice.

L'âme dévote de l'empereur, conclut le jésuite, s'est envolée comme un aigle de ce monument [...], vers le séjour de tous les pieux héros chrétiens, vers le séjour de l'immortalités7.

Par un subtil renversement de perspective, le défunt construit ici son propre éloge, matérialisé par le bûcher funèbre. L'orateur s'efface derrière cet artifice qui confère à l'éloge l'apparence de la véracité.

$\mathrm{Au}$ sommet du castrum doloris, le spectateur aperçoit une scène qui pourrait être comprise comme une figuration de l'apothéose à la romaine : l'archiduc Ferdinand III se tient debout, les pieds posés sur une couronne qui forme la clef de voûte de l'édifice. Représenter l'effigie du défunt sur l'appareil funèbre est une tradition ancienne. Ici, le corps glorieux du défunt porte sur son dos un globe surmonté d'un bonnet archiducal sur lequel un aigle se tient perché. Deux figures féminines (elles pourraient être les deux épouses de Ferdinand III, Anna Maria et Anna Leopoldina, toutes deux décédées avant leur époux ${ }^{58}$ ), semblent soutenir à la fois le bonnet et le globe, deux symboles de domination $^{59}$. Le caractère éclectique de cette figuration rend difficile son interprétation $^{60}$. On peut supposer qu'il s'agit d'une transposition chrétienne de l'apothéose des empereurs romains. L'architecte étant inconnu, on peut se demander si ce n'est pas le prédicateur lui-même qui a donné des instructions pour le castrum doloris, en restant anonyme par modestie, comme le fit vraisemblablement Thomas Winter.

En 1705, de telles correspondances entre éloquence et architecture funèbre sont devenues routinières dans les funérailles impériales organisées par les jésuites en Autriche, en Bohême et dans l'Empire. On peut supposer qu'à Graz, en 1705, pour les funérailles organisées par le Collège et l'Université jésuites, le catafalque obéissait également à un programme défini par les Pères ${ }^{61}$. En 1705, à Breslau/ Wroclaw en Silésie, le jésuite Johann Kugler prononce, toujours en l'honneur de Léopold $\mathrm{I}^{\mathrm{er}}$, un discours en latin ${ }^{62}$ qui reprend l'argument du catafalque éphémère, centré sur l'anagramme «Leopoldus/ Sol Duplus» («Léopold, double soleil »). En haut de l'édifice figure un grand soleil portant cette inscription ${ }^{63}$. Toujours en 1705, à Znaim/ Znojmo, ville du Sud de la Moravie (aujourd'hui: au Sud de la République tchèque), qui possédait son collège jésuite, l'oraison funèbre du jésuite Andreas Sax, comme celle de 
notre prédicateur Thomas Winter, suit point par point l'argument du castrum doloris : les douze chapitres $d u$ discours correspondent aux douze statues des Vertus représentées sur l'édifice funèbre ${ }^{64}$. À Ratisbonne, en 1705, le prédicateur jésuite, dans la dédicace de son oraison funèbre ${ }^{65}$, décrit le castrum doloris et affirme avoir été invité à en concevoir le programme. Ces connivences ne se rencontrent pas uniquement dans les cérémonies orchestrées par les jésuites : toujours en 1705, la Confrérie espagnole du Saint Sacrement confie à l'historiographe de la Cour, Johann Baptist Comazzi, la rédaction d'un éloge en latin et simultanément l'invention des inscriptions du castrum doloris érigé dans l'église Saint-Michel de Vienne ${ }^{66}$. Si les jésuites jouent un rôle prépondérant dans l'art funèbre ${ }^{67}$, ils n'en ont pas le monopole.

En 1740, à la mort de Charles VI, on ne trouve plus que quelques rares exemples d'une telle symbiose entre architecture et éloquence funèbre : dans l'église Saint-Michel de Vienne, en 1741, l'idée de la " grandeur impériale » est présente à la fois dans le castrum doloris érigé par l'architecte Franz Anton Danne, et dans l'oraison funèbre de Pius Manzador ${ }^{68}$. Aux obsèques de l'empereur François-Étienne (1765) et de l'impératrice Marie-Thérèse (1780), le catafalque éphémère est presque complètement passé de mode $^{69}$.

26 L'édifice et la décoration funèbre offrent des arguments pour l'«illustratio » et l'« amplificatio ». En s'appuyant sur eux, Thomas Winter invite les auditeurs à communier à une consolation qui se veut universelle, à s'associer à la liturgie en mobilisant leurs sens :

Ces très nombreux cierges et flambeaux, qui rayonnent d'une telle clarté, doivent allumer dans le cœur de tous les croyants une lumineuse espérance, et chasser toute tristesse et toute affliction. Voici cette espérance: qu'il soit accordé [à Léopold $\mathrm{I}^{\mathrm{er}}$ ] d'être enveloppé de cette éternelle clarté devant la face du Père des lumières ; lui qui, depuis son aurore jusqu'à son déclin, a rayonné comme le grand soleil universel ${ }^{70}$.

On sait l'importance de l'imagination dans les Exercices spirituels d'Ignace de Loyola. Dans la cérémonie funèbre, «les interactions rhétoriques entre l'architecture et le discours $^{71}$ ", la correspondance des symboles, le jeu des allusions, la répétition des topoi intensifient l'effet produit par le discours. Les cierges, symbole d'espérance, reflètent en outre la gloire de l'empereur, assimilé à un soleil. Cette métaphore filée illustre la fécondité de l'imagination du jésuite.

Chez d'autres prédicateurs, la description du catafalque, généralement dans l'exorde, vise à augmenter l'effet pathétique, à plonger les auditeurs dans une tristesse encore plus grande. La représentation tridimensionnelle accroit l'évidence (« evidentia») des vertus et des exploits («virtutes et res gestae »), et renforce l'admiration.

Le Temple de la Douceur de Thomas Winter peut être qualifié d'architecture rhétorique. Les allégories, symboles et emblèmes qui servent $d$ '« ornatus » sont autant de figures et de tropes.

Que pourrait-on inventer de plus parfait pour la louange et la consolation ? Et qu'est-ce que cette oraison funèbre de louange et de consolation pourrait ou devrait s'employer à démontrer? Si ce n'est ce qui est représenté et que nous contemplons dans ce castrum doloris richement illuminé sous nos yeux, à savoir la douceur trois fois bienheureuse de Léopold ${ }^{72}$.

Thomas Winter met en avant l'appareil funèbre comme une source d'inspiration qui confère à son discours l'apparence de l'objectivité et la force de l'évidence. Dans la 
péroraison, l'évocation du castrum doloris vient illustrer un ultime argument: Dieu couronne la douceur de Léopold, comme jadis celle du roi David :

Et c'est pourquoi ce monument en l'honneur de la Mansuétude trois fois

bienheureuse de Léopold est orné d'une si imposante couronne ${ }^{73}$.

Cette couronne, symbole de la béatitude éternelle de Léopold, constitue le sommet du castrum doloris, et le but ultime de l'« argumentatio »:

Mon discours d'éloge et d'honneur étant parvenu jusqu'à la couronne de ce monument de louange et d'honneur, c'est-à-dire à la béatitude de Léopold, il convient qu'il s'achemine vers $\mathrm{sa} \mathrm{fin}^{74}$.

L'exercice de décryptage du monument et de visualisation du discours touche à sa fin. Par le génie rhétorique du prédicateur jésuite, les vertus abstraites se sont incarnées sous les yeux des auditeurs dans une scène allégorique vivante et dans des symboles qui seuls sont à même de rendre compte des « ineffables vertus » du défunt.

Le recours aux symboles, aux allégories et au castrum doloris comme ornement du discours est caractéristique de l'éloquence ingénieuse et fleurie telle que la théorisent notamment Nicolas Caussin et Gérard Pelletier ${ }^{75}$. De nombreux orateurs tirent argument du castrum doloris pour prouver la vertu de l'empereur. Ainsi dans une oraison funèbre de Liborius à Sancta Barbara en l'honneur de Charles VI, en 1740 : «Ce que je dois dire sur notre prince territorial, je le tire des symboles de vertus qui ornent ce catafalque ${ }^{76}$. " L'éloge architectural fournit les arguments de l'éloge oratoire. La représentation se fonde, non sur le réel, mais sur d'autres représentations, architecturales, picturales et symboliques. La référence à la réalité disparait. La vertu est définie comme ce qui est digne d'éloge. L'éloge est donc à la fois le fondement de la vertu, et sa récompense. L'empereur est vertueux et digne d'être pleuré, parce que le castrum doloris le représente comme tel. Le raisonnement devient tautologique. Les termes «Lob» («éloge ») et «Tugend» («vertu») deviennent quasiment interchangeables, et fusionnent dans la notion de «Zierde » (" grâce », « ornement »).

30 À la même époque, les jésuites sont également les "grands contributeurs ${ }^{77}$ » dans le domaine de l'emblématique, système symbolique qui «associ[e] une syntaxe iconique visuelle à une syntaxe grammaticale ${ }^{78} »$. Les recueils d'emblèmes, composés principalement par des jésuites « dans les provinces belges ou germaniques entre 1600 et $1625^{79}$ » servaient de répertoires d'idées pour les prédicateurs. À l'occasion, des "cartes emblématiques peintes" pouvaient être déroulées du haut de la chaire, pour illustrer les propos de l'orateur ${ }^{80}$. De même, lors des obsèques impériales, des emblèmes retraçant les vertus du défunt étaient fréquemment fixés sur les murs ou les colonnes de l'église, ou bien sur l'édifice funèbre ${ }^{81}$.

\section{L'enjeu du discours : la représentation du prince idéal et de ses vertus}

31 L'orateur a pour devoir de montrer, pour que le spectateur regarde et admire les vertus impériales. L'importance de la vertu princière est un héritage du stoïcisme, dont la forme romaine a imprégné l'humanisme européen ${ }^{82}$. C'est la raison pour laquelle une majorité de prédicateurs adopte une disposition «per virtutes». Cette structure caractérise également les miroirs du prince circulant à l'époque, notamment le Princeps in compendio ${ }^{83}$ (1632), qui servit à l'éducation de Ferdinand III, de Léopold $\mathrm{I}^{\text {er }}$ et de Charles VI, et les Vertus de Ferdinand II de Guillaume Lamormain $\left(1638^{84}\right)$, confesseur 
jésuite de Ferdinand II. De nombreuses oraisons funèbres prennent pour objet une ou plusieurs vertus : la sagesse ${ }^{85}$, la saintetée ${ }^{86}$, la piétée ${ }^{87}$, la constance et la force, d'après la devise de Charles VI ( (Constantia et fortitudine $\left.{ }^{88} »\right)$; ou encore la sagesse, la mesure, la force et la justice ${ }^{89}$.

Le choix de se concentrer sur la douceur était original, voire osé. Les catalogues de vertus évoquaient la clémence et son pendant, la justice. Mais si la «clementia " ( Milde ») était un attribut traditionnel du monarque, la «mansuetudo» («Sanfftmuth») pouvait être interprétée comme de la faiblesse. Thomas Winter a sans doute voulu créer la surprise, qualité essentielle de l'éloquence ingénieuse ${ }^{90}$. Dans sa préface au livret funèbre publié lors des obsèques officielles à Saint-Augustin en 1705, l'auteur anonyme fait observer que l'appareil funèbre suscitera l'étonnement ("Verwunderung ») du spectateur ${ }^{91}$. Le "goût pour la pensée brillante " («ingenium $\left.{ }^{92} »\right)$ pénètre dans l'espace de langue allemande par l'intermédiaire du jésuite Jacob Masen ${ }^{93}$ qui fut, avec Cyprian Soarez, l'auteur le plus publié en Allemagne au cours du XvII ${ }^{\mathrm{e}}$ siècle ${ }^{94}$.

L'Ars nova argutiarum [de Masen], écrit Barbara Bauer, est basé sur le postulat esthétique de la nouveauté et de la surprise. [Son but] est de surprendre le lecteur, l'auditeur ou le spectateur par des idées ingénieuses, des pensées originales, des combinaisons inattendues entre les mots et les idées. [...] Le summum de l'invention et de l'élocution consiste à solliciter la perspicacité ("Scharfsinn ») de l'auditeur par des énigmes, des effets de distanciation, en rapprochant des choses opposées ou paradoxales ${ }^{95}$.

\section{Un anti-machiavélisme d'inspiration néo-stoïcienne}

Tout le discours de Thomas Winter reflète les discussions contemporaines sur l'idéal du prince chrétien et le meilleur gouvernement. À la fin de son exorde, le prédicateur condamne

le jugement des gens du siècle, selon qui les fondements de la félicité terrestre résident non dans la vertu, mais dans de vaines et changeantes pensées sur l'État ${ }^{96}$.

Il critique ainsi implicitement le réalisme politique inspiré par Machiavel. Il s'inscrit dans la lignée du jésuite bavarois Adam Contzen, l'un des plus virulents représentants de "l'anti-machiavélisme allemand ${ }^{97}$ ", qui s'efforça de réconcilier l'idéal et la réalité du pouvoir, la puissance et la vertu. Contzen considérait la piété comme «la première caractéristique d'un État fort ${ }^{98} »$. On trouve chez Thomas Winter la même idée, qui s'appuie ici sur l'argument d'évidence :

D'après le jugement des gens du siècle [...], par la douceur et la clémence, un prince perd sa couronne et son sceptre, ses pays et ses royaumes. Mais le fait est que la réalité est tout autre: un prince plein de douceur reconquiert tout ce qu'il avait perdu, et agrandit ce qu'il possédait déjà'.

Dans les Virtutes de Lamormain, on pouvait déjà lire que Ferdinand II avait rejeté « les louvoiements des politiques hypocrites» au profit des «principia» (c'est-à-dire des fondements divins du pouvoir ${ }^{100}$ ).

$\mathrm{Au}$ début de la première partie, dans une longue prolepse, Winter justifie encore le thème de son discours et réfute par avance les arguments de ceux qui jugeraient contraire à la bienséance un éloge de la douceur princière :

Pourvu que personne ne soit hostile à cet exposé, le jugeant impropre à l'éloge et à

la gloire de la plus grande dignité du monde ${ }^{101}$.

Pour donner davantage de force à sa "probatio", Winter accumule les citations : saint Ambroise, Pomponius Laetus, Justinien, saint Basile, saint Jean Chrysostome, saint 
Grégoire de Nazianze et Thémistius ${ }^{102}$ voient dans la douceur une qualité essentielle du monarque, et le principal sujet d'éloge. Si Thomas Winter déploie un tel arsenal argumentatif, c'est que l'enjeu est de taille, car il s'agit de l'image du prince :

Ainsi, conclut-il, que personne ne s'égare à considérer que [mon discours] défigure

l'image de Léopold, vivant tableau de toutes les [...] vertus ${ }^{103}$.

$\mathrm{Au}$ contraire, un « esprit ingénieux » se reconnaît à sa capacité à

résumer ou englober les vertus presque infinies de l'empereur, de telle façon que notre pauvre éloquence ne soit pas dépassée par la surabondance d'épisodes dignes de louanges ${ }^{104}$.

La justification du thème de l'oraison funèbre s'achève ainsi sur le topos du sujet qui dépasse la parole ("materia transcendat opus»). Avec une nouvelle salve de citations (Saint Jean Chrysostome, Saint Grégoire de Nazianze, Themistius et Cornelius a Lapide), Winter énumère ensuite par «inclusio » toutes les qualités contenues dans la douceur. Celle-ci consiste essentiellement, enchaîne-t-il, en une "maîtrise parfaite de tous les mouvements naturels de l'âme ${ }^{105}$ ».

La première partie, centrée sur l'«agrandissement du royaume terrestre ", évoque principalement la reconquête par Léopold $\mathrm{I}^{\mathrm{er}}$ de la Hongrie sur les Turcs: ceux-ci reculent devant la «terrifiante vertu ${ }^{106}$ » de Léopold, plus puissante que «l'ardeur belliqueuse et les secrets de la stratégie ${ }^{107}$ ». Le raisonnement se poursuit avec une série d'antonomases : Léopold est le nouvel Auguste, le nouveau Moïse, le David autrichien, le nouveau Théodose, et enfin le nouveau Constantin ${ }^{108}$.

Winter développe ensuite la répugnance dont faisait preuve Léopold $\mathrm{I}^{\mathrm{er}}$ vis-à-vis de la guerre, son souci de ne pas verser le sang ${ }^{109}$. Ainsi le prédicateur présente-t-il sous un jour positif certains aspects controversés de la personnalité et de la politique de Léopold I ${ }^{\text {er }}$. Jutta Schumann cite des libelles («Flugblätter») protestants qui voient en Léopold I ${ }^{\text {er }}$ un empereur faible, sans aucune aptitude à la guerre (l'empereur ne s'était jamais rendu sur un champ de bataille), cédant à l'influence de ses conseillers jésuites ${ }^{110}$.

37 Les autres oraisons funèbres de 1705, comme de nombreux libelles, louent l'attitude de l'empereur sur la scène internationale; elles présentent, comme Thomas Winter, un Léopold pacifique, tenant toujours parole, respectant le droit et les traités, enclin à la clémence, répugnant à verser le sang, et menant des guerres uniquement défensives, par opposition au roi de France, accusé de mener une politique agressive, multipliant les ruptures de traités et paré des mêmes vices que les Turcs (cruauté, cynisme ${ }^{111}$ ). Lorsqu'elles abordent les guerres contre les Turcs, ces mêmes oraisons funèbres louent abondamment le zèle religieux, la force et les victoires éclatantes de Léopold $\mathrm{I}^{\mathrm{er}}$, remportées grâce à la protection de la Providence qu'il avait su s'attirer par sa vertu et sa piété. Léopold est stylisé en "empereur de guerre », en "miles christianus » dans la lignée de Charles Quint ${ }^{112}$, bien qu'il n'ait jamais mené personnellement de campagne. Il faut remarquer l'absence de ce topos dans l'oraison funèbre de Thomas Winter, qui impute les victoires militaires de Léopold $\mathrm{I}^{\mathrm{er}}$ exclusivement à sa douceur ainsi qu'à sa soumission à la volonté de Dieu, que Cornelius a Lapide considère comme deux vertus inséparables ${ }^{113}$.

38 Cet abandon à Dieu se manifeste en particulier dans les moments désespérés (notamment le siège des Turcs en 1683). D'après des notes du confesseur impérial, le $P$. Philippe Miller, Thomas Winter rapporte des paroles d'abandon à la Providence prononcées par l'empereur ${ }^{114}$. L'inspiration stoïcienne est sensible, mais il est probable que Thomas Winter se souvient également ici de la célèbre anecdote du «Crucifix de 
Ferdinand II ». Cet épisode est rapporté par Guillaume Lamormain ${ }^{115}$. Suite à une audience mouvementée (la «Sturmpetition » du 5 juin 1615 ${ }^{116}$ ), au cours de laquelle les États protestants d'Autriche tentèrent d'arracher à l'empereur Ferdinand des concessions en matière religieuse, le comte Heinrich Matthias von Thurn et les rebelles de Bohême assiégèrent Vienne. Un matin, alors que le confesseur de Ferdinand II, le jésuite Bartholomée Viller, entrait dans la chambre de l'empereur, il trouva celui-ci prosterné, face contre terre, devant un crucifix. "Beaucoup, affirme Lamormain, racontèrent que le Christ avait parlé à Ferdinand par un Crucifix, l'encourageant et le réconfortant ${ }^{117}$. " Le «non te deseram ${ }^{118}$ » du Christ à Ferdinand II est cité dans de multiples oraisons funèbres. Ce récit joue un rôle important dans la représentation de la « pietas austriaca».

\section{La « douceur habsbourgeoise » contre la superbe des Bourbons}

Le choix de la " douceur » comme thème d'une oraison funèbre a, nous l'avons vu, une portée polémique. On peut y voir une critique de la superbe de Louis XIV, thème fréquent dans les oraisons funèbres, les miroirs du prince et dans les libelles. Nous ne retracerons pas ici les étapes de la longue rivalité franco-autrichienne, qui culmina, à la fin $d u x$ III $^{e}$ et au début du XVIII $^{\mathrm{e}}$ siècle, dans la guerre de la Ligue d'Augsbourg (1689-1697) et dans la guerre de Succession d'Espagne (1701-1714119). L'allégorie de la Douceur de Thomas Winter fait partie des représentations artistiques qui manifestent " une affirmation forte de la conscience dynastique ${ }^{120}$ » habsbourgeoise, en réaction contre les prétentions françaises. Elle prend place dans la "guerre des images ${ }^{121}$ » qui se joue par l'intermédiaire de différents médias : gravures imprimées sur les libelles, effigies sur les monnaies, peinture, statuaire ${ }^{122}$... En 1685-1686, Louis XIV fit ériger, à Paris et dans plusieurs villes de province, une série de statues équestres visant «à s'attacher l'adhésion du plus grand nombre ", à "faire communier les sujets dans la représentation d'une monarchie de gloire ${ }^{123} »$. La statue de Louis XIV conçue pour la place Notre-Dame des Victoires ${ }^{124}$ suscita l'indignation de l'Europe, car elle portait sur son socle l'inscription « À l'homme immortel » (« Viro Immortali »).

Thomas Winter veut affirmer la supériorité de la douceur sur l'ardeur guerrière et l'intransigeance. D'ordinaire, les trophées militaires sont omniprésents dans la décoration funèbre. Ici, ils se font discrets : quelques étendards et deux tambours sur le podium. L'attitude de Léopold $\mathrm{I}^{\mathrm{er}}$ sur le castrum doloris est inspirée par la colonne de la Peste (Vienne, "Am Graben»), achevée en 1692. Celle-ci résume la vision qu'avait l'empereur de la fonction monarchique et de ses pays héréditaires. L'empereur à genoux, implorant la Trinité, est le symbole de la " pietas austriaca ", vertu " héréditaire et dynastique» des Habsbourg ${ }^{125}$. L'humilité est érigée ostensiblement en vertu princière. Comme le précise T. Brockmann,

l'historiographie contemporaine faisait déjà référence à la Colonne de la Peste pour souligner combien Léopold $\mathrm{I}^{\mathrm{er}}$ et son cousin Louis XIV étaient différents dans la conscience qu'ils avaient de leur dignité, et dans les représentations qu'ils se faisaient d'eux-mêmes ${ }^{126}$.

Dans la deuxième partie de son oraison, consacrée à la " conquête des cœurs humains par la douceur ", Thomas Winter donne plusieurs exemples concrets de l'« humilité " de Léopold $\mathrm{I}^{\mathrm{er}}$. Comme beaucoup d'autres prédicateurs, il évoque notamment le lavement des pieds des pauvres effectué par Léopold $\mathrm{I}^{\text {er }}$ à l'occasion de l'élection impériale à Francfort en 1658. 
42 Winter décrit les liens d'amour réciproque entre le prince et ses sujets, dont l'obéissance est obtenue par la douceur. Sous la plume du jésuite, l'anti-portrait du prince machiavélien haï et craint par ses sujets s'incarne en Léopold I ${ }^{\mathrm{er}}$.

\section{Défense et illustration de la politique hongroise de Léopold ler}

La deuxième partie de l'oraison funèbre accorde une place importante à un topos omniprésent dans les représentations des Habsbourg : celui de la clémence, « âme de la vieille Autriche ${ }^{127} »$. L'empereur a porté si loin l'exercice de cette vertu, qu'il s'est rendu semblable à Dieu : cette idée est développée en six points avec l'anaphore « Semblable à Dieu en tout ${ }^{128}$ ", et amplifiée à l'aide de nombreux exemples et citations historiques, notamment tirées du De Clementia de Sénèque. Derrière cette apologie de la clémence, il faut déceler les efforts de Winter pour défendre la politique hongroise de l'empereur.

Depuis les traités de Westphalie, la tendance était à l'unification politique et religieuse de la monarchie autrichienne, selon le «modèle austro-bohême » déployé à partir de $1627^{129}$.

La défense de la religion catholique n'avait pas pour seul fondement le bien-être spirituel [des] sujets, mais une impérieuse nécessité politique. Dans une monarchie où étaient juxtaposés des États, des nations et des cultures si divers, la communauté de religion pouvait fournir un élément d'unité. Réciproquement, la religion n'était pas seulement une affaire privée, mais le moyen de manifester son opposition et de traduire des aspirations particularistes. [...] C'est pourquoi le gouvernement de Vienne admettait depuis Juste Lipse que la religion catholique était un principe fondamental d'unité dans un ensemble politique englobant tant de peuples et d'États ${ }^{130}$.

Certains magnats hongrois et leurs sujets s'étaient convertis au calvinisme, tandis que les notables et bourgeois allemands de Hongrie étaient largement passés au luthéranisme. La crise de 1664, déclenchée par la paix de Vasvár avec les Turcs, devait fournir au gouvernement de Vienne l'occasion de briser la résistance des ordres de Hongrie, et d'imposer un programme de Contre-Réforme intransigeant dans la Couronne de Saint-Étienne. Les Hongrois condamnèrent unanimement le traité de Vasvár :

Ils accusaient la Maison d'Autriche de livrer leur pays aux incursions ottomanes, alors que les armées chrétiennes étaient victorieuses, et reprochaient à l'empereur de sacrifier leur pays à des intérêts allemands, voire à des préoccupations purement dynastiques. Les magnats catholiques, les membres du gouvernement de Presbourg et l'archevêque de Strigonie lui-même se retrouvèrent dans une vaste conjuration anti-autrichienne ${ }^{131}$.

La «conjuration des magnats» fut découverte en 1671, et les trois principaux responsables furent arrêtés, jugés et exécutés. Les protestants furent poursuivis et chassés, leurs biens confisqués ${ }^{132}$. En effet, «bien que la conjuration fût largement le fait de nobles catholiques, Léopold $\mathrm{I}^{\mathrm{er}}$ et ses ministres croyaient toujours que l'hérésie et la rébellion étaient liées ${ }^{133}$ ». L'action répressive de l'évêque Kollonich, nommé président de la Chambre de Hongrie en 1672, fut violemment critiquée dans l'Empire. La condamnation aux galères de 40 prédicateurs protestants qui avaient refusé de se convertir suscita une vague d'indignation parmi les protestants allemands, «juste au moment où Vienne tentait de rassembler la Hollande, le Brandebourg et la Saxe dans une alliance contre la France ${ }^{134} »$. Finalement, la menace française, qui unit les protestants autour de l'empereur, "permit à la cour de Vienne de limiter, dans 
l'Empire, la dégradation de l'image [de Léopold Ir] induite par sa politique religieuse agressive en Hongrie ${ }^{135}$ ».

La plupart des oraisons funèbres évoquent la conjuration des magnats hongrois. Celle de Thomas Winter ne fait pas exception. Cette affaire avait fait grand bruit dans la presse des années 1670 , à Vienne et dans l'Empire ${ }^{136}$. Ceci confirme le rôle des oraisons funèbres impériales comme relai des médias. Les nombreux faits évoqués par Winter reprennent les informations sur la conjuration et sur les procès que le public viennois avait pu lire dans les libelles et les journaux.

Conformément aux exigences du genre funèbre, Winter ne cite pas de noms ni de dates. Lorsque Léopold refusa des libertés religieuses aux protestants, sa douceur leur rendit ce refus "plus supportable", affirme-t-i $\left.\right|^{137}$. L'empereur convertit les peines capitales en emprisonnement, et s'efforce de faire libérer des prisonniers. Winter évoque la répugnance de Léopold $\mathrm{I}^{\mathrm{er}}$ à signer une condamnation à mort, et les efforts déployés pour atténuer les souffrances d'un condamné lors de son exécution. L'empereur se montre ainsi semblable à Auguste qui, comme le rapporte Sénèque, « semblait être puni lorsqu'il punissait ${ }^{138}$.»

L'empereur veut épargner aux condamnés les souffrances dans l'au-delà, en faisant célébrer des milliers de messes pour le repos de leur âme ${ }^{139}$. Avant de faire exécuter les prisonniers "qu'il n'était plus totalement libre de sauver de l'épée ${ }^{140}$ ", Léopold s'assurait que « leur peine ne serait pas reportée sur leurs descendants ». Il résistait en cela à « certains zélateurs d'une justice plus sévère, qui tentaient de le pousser à priver tous les descendants des condamnés à mort de leurs titres de noblesse ${ }^{141}$.» Derrière cette allusion, on perçoit la lutte, à la cour de Vienne, entre les défenseurs d'une Contre-Réforme impitoyable en Hongrie, et le parti des modérés ${ }^{142}$.

Winter voit dans l'attitude de Léopold I ${ }^{\text {er }}$ à l'encontre de ses ennemis une nouvelle preuve de la douceur impériale :

Il ne sied point à une majesté impériale de supprimer ses ennemis par des intrigues secrètes, par le poison ou d'autres moyens qui conviennent mal à un prince, et qui relèvent davantage de la vengeance que de la sanction. Il ne saurait les employer sans offenser sa haute dignité, qui reflète l'autorité de Dieu sur le monde. Ces ennemis doivent être poursuivis par les armes ; lorsqu'ils ont été capturés, c'est par un tribunal qu'ils doivent être condamnés à l'exécution, à cause de leur félonie, dans un but dissuasif ${ }^{143}$.

Le prédicateur rapporte une autre «res gesta » du même ordre : Léopold mit tant de temps pour signer la condamnation d'un serviteur félon, qu'il parvint à ralentir une procédure de mise à mort qu'il jugeait barbare et peu chrétienne. Il donna ainsi au fautif le temps de s'échapper. Winter apporte à cette attitude la caution de Sénèque (De Clementia) et de Cicéron (Pro Marcello).

Winter s'efforce d'offrir à ses auditeurs un tableau vivant enrichi d'histoires inédites, loin des catalogues de vertus stéréotypés répétés en boucle par la plupart des prédicateurs, qui citent généralement peu de faits précis. L'accumulation des exemples illustrant la clémence (Winter fait successivement référence à Hadrien, Théodose, Rodolphe $\mathrm{I}^{\mathrm{er}}$ de Habsbourg, Trajan, Auguste, David, Marc-Aurèle et Justinien ${ }^{144}$ ) et leur amplification par des citations particulièrement nombreuses et variées montrent aussi le zèle déployé par le prédicateur pour justifier la politique hongroise de l'empereur, inspirée et soutenue par ses confrères jésuites. 


\section{Patience, justice et sagesse : modèles antiques et bibliques}

éveloppements suivants sont consacrés à la patience, plus divine qu'humaine, dont Léopold aurait fait preuve face à ses contradicteurs. Plusieurs citations d'auteurs antiques illustrent et amplifient la capacité de l'empereur à «ne pas s'impatienter devant les plaintes et les insultes grossières, mais leur opposer une douceur inébranlable ${ }^{145} »$. Comme c'est le cas tout au long du sermon, ces références érudites sont entrecoupées par le récit d'épisodes réels, ponctués par la quintuple anaphore «Les dieux sont tolérants » (« Dii tolerant »), tirée du discours de Libanios sur Théodose. Le but est de démontrer que Léopold s'est rendu semblable à Dieu par sa douceur. Winter évoque la réaction de Léopold lors d'un office religieux perturbé par un forcené réclamant justice : l'empereur ordonna qu'il ne lui soit fait aucun mal, affirmant qu'il ne voulait empêcher personne de trouver refuge dans une église ${ }^{146}$. Une nouvelle comparaison avec Théodose conclut le développement.

51 Le prédicateur applique ensuite à Léopold les différents degrés de la douceur énumérés par Cornelius a Lapide :

Les degrés de la douceur par lesquels on parvient à la félicité promise [...] sont : 1 . se montrer aimable avec tout le monde, cœur et paroles empreints de douceur; 2. Opposer à la colère de son prochain des réponses douces et bonnes. 3. Supporter en silence et dignement les dommages, les vols, sans se montrer offensé. 4. Et même, en témoigner une certaine joie. 5. Vaincre la méchanceté et l'hostilité des ennemis par la douceur et la bonté ; s'efforcer autant que possible de se concilier ses ennemis ${ }^{147}$.

Cette dernière recommandation rappelle Juste Lipse, théoricien de la prudence politique. Mais Winter s'efforce ici avant tout d'édifier son auditoire, en mettant l'accent sur les vertus impériales qui peuvent et doivent être imitées par les fidèles. Il tente - exercice délicat - de concilier l'«instructio» et l'« aemulatio " avec l'autre finalité essentielle de l'oraison funèbre, à savoir la louange, et de maintenir l'équilibre entre ces différents objectifs. Une symbiose s'opère entre l'influence stoïcienne, distillée au gré des citations d'auteurs antiques (notamment Cicéron, Sénèque, et une citation de Tacite ${ }^{148}$ ), et l'exégèse des Pères de l'Église et des auteurs modernes, principalement jésuites : Johannes Velazquez ${ }^{149}$, Gaspar Sanchez ${ }^{150}$, Cornelius a Lapide, Louis de Grenade ${ }^{151}$ et quelques autres.

Sont ensuite évoquées la justice, pendant de la clémence, et la sagesse ${ }^{152}$. Après une nouvelle accumulation de citations, le prédicateur brosse un tableau de Léopold $\mathrm{I}^{\mathrm{er}}$ se laissant approcher par les mendiants, avec une citation de la bouche de l'empereur: « Laissez donc les pauvres venir librement à moi ${ }^{153}$ ».

Winter compare ces paroles à celles prononcées par le "Patriarche autrichien » Rodolphe $\mathrm{I}^{\mathrm{er}}$, qu'il cite d'après les Monita et exempla politica de Juste Lipse :

Laissez donc, pour l'amour de Dieu, approcher de moi tous les hommes qui le désirent. Car je n'ai pas été appelé au gouvernement pour être enfermé dans un coffre-fort ${ }^{154}$

En citant le célèbre miroir du prince de Juste Lipse, Winter montre que Léopold I ${ }^{\text {er }}$ correspond à l'idéal du prince chrétien. Le topos de la comparaison avec les ancêtres a pour but d'inscrire le défunt dans une tradition dynastique, et d'affirmer le caractère héréditaire des "vertus habsbourgeoises». Pour Olivier Chaline, dans les pays de la Maison d'Autriche, la dynastie habsbourgeoise est fortement mise en avant par les représentations et discours à visée panégyrique. Il n'en est pas de même en France : la 
dynastie des Bourbons est moins présente, l'image du roi est davantage centrée sur la personne de Louis XIV ${ }^{155}$.

Winter va ensuite chercher dans la vox populi une preuve supplémentaire de la vertu de Léopold. Dans une apostrophe pleine de pathos, il invite tous les pays de la Monarchie, et en particulier les habitants de Vienne, à témoigner qu'ils ont été touchés personnellement par la vertu de l'empereur ${ }^{156}$. Le prédicateur dépeint l'affliction des Viennois en 1668, lorsque l'empereur faillit succomber après avoir ingéré par mégarde une substance toxique ${ }^{157}$. Léopold gouvernait comme un père gouverne ses fils, ainsi que le recommandait Agésilas ${ }^{158}$, affirme Winter, pour qui le prince, contrairement à celui de Machiavel, doit être aimé plutôt que craint.

Cet appel au témoignage de tous les Viennois «sincèrement dévoués à la vérité catholique ${ }^{159}$ » est si vibrant, que l'on se demande si Winter ne tente pas ici de couvrir les voix critiques à l'encontre de l'empereur. Il va de soi que Winter n'en appelle pas au témoignage des protestants de l'Empire : ceux-ci ne sauraient s'associer à un tel concert de louanges.

Sur le même ton, une hypotypose pathétique du siège de Vienne par les Turcs en 1683 campe un Léopold demeurant contre vents et marées dans sa capitale, sourd aux supplications de ceux qui voudraient l'éloigner de la ville encerclée : "C'est à Vienne que je suis le plus en sécurité1 $160 »$. En vertu de cette attitude héroïque, Winter décerne solennellement à Léopold le titre de « Père de la patrie ", à grand renfort d'anaphores, de citations et d'amplification ${ }^{161}$. Le jésuite ne précise pas que Léopold $\mathrm{I}^{\text {er }}$, qui s'était dans un premier temps mis à l'abri à Passau avec la cour, avait gagné Dürnstein au moment de la contre-offensive, afin de ne pas blesser la susceptibilité du roi de Pologne Jean III Sobieski, à qui Charles V de Lorraine avait laissé le commandement ${ }^{162}$. Cette mise en retrait lui fut vivement reprochée. Ceci explique l'envolée de Winter, qui s'efforce de faire apparaître Léopold I $^{\text {er }}$ comme le vrai défenseur de Vienne.

Dans aucune des trois parties, Thomas Winter ne donne dans la diatribe anti-française. L'éloquence épidictique et son style élevé s'accommodent mal de la polémique. Le prédicateur s'emploie à convaincre par son érudition. On dénombre au total deux-centdix citations, pour un sermon de soixante-dix-neuf pages. Presque toutes sont des citations primaires, seize seulement des citations secondaires (puisées dans des florilèges et compilations). Dans la deuxième partie, la plus longue (trente pages), sur quatre-vingt-cinq citations, on compte trente-neuf citations chrétiennes (dont dix-sept citations des Écritures, quinze des Pères de l'Église ${ }^{163}$, et sept d'exégètes modernes ${ }^{164}$ ) pour trente-quatre références et citations tirées de l'Antiquité païenne ${ }^{165}$, et douze citations tirées d'ouvrages médiévaux ou modernes d'histoire et de morale, ou de florilèges modernes ${ }^{166}$. Le savant entrelacs d'auteurs chrétiens et païens manifeste l'assimilation par les jésuites de la pensée «des païens aveuglés par l'erreur ${ }^{167}$ ». Le topos du dépassement de l'Antiquité païenne est omniprésent.

Le portrait de Léopold $\mathrm{I}^{\mathrm{er}}$ que brosse Thomas Winter se distingue par son insistance sur les traits christiques qu'il prête à l'empereur: doux et patient, celui-ci ne répond pas aux injures, tel Jésus devant Pilate, et rend le bien pour le mal. Il se laisse approcher par les pauvres comme le Christ. La vox populi elle-même proclame sa réputation de sainteté. Il est fort probable que Thomas Winter entendait ainsi apporter des arguments au procès de canonisation que certains réclamaient pour Léopold $\mathrm{I}^{\mathrm{er}}$. $\mathrm{Si}$ l'historiographie actuelle ne met pas en doute sa piété et une certaine forme de 
clémence, il faut pourtant, aux yeux de Jean Bérenger, "nuancer l'image d'un Léopold $\mathrm{I}^{\text {er }}$ doux, pieux, humble et pacifique, éternelle victime des agresseurs turcs ou français ${ }^{168}$ ». Son attitude offensive pendant la guerre de Succession d'Espagne, avec son intervention militaire en Italie dès 1701 , montre à quel point il était conscient de ses prérogatives et prêt à défendre les intérêts de sa Maison. Olivier Chaline est du même avis :

L'empereur Léopold hésitait longtemps et avait besoin de temps pour se décider. Mais lorsqu'il s'était enfin décidé, il se montrait toujours très résolu et opiniâtre, surtout quand il s'agissait de la religion, de la dignité impériale ou de la défense de sa Maison ${ }^{169}$.

Mais laissons de côté l'épineuse question de la vérité du portrait, du récit, de la représentation.

Thomas Winter s'inscrit dans la défense de la "politica christiana", un ensemble de théories politiques dans lesquelles l'exercice du pouvoir est limité par des normes théologiques ${ }^{170}$. Le prince tient son pouvoir de Dieu; il est le protecteur de ses sujets et de l'Église et gouverne dans le cadre d'une « monarchia temperata » ou « monarchia mixta ».

Léopold $\mathrm{I}^{\mathrm{er}}$ se concevait comme un prince chrétien et non comme un «monarque absolu », un mot qui manquait à son vocabulaire, comme le mot « raison d'État »"171.

L'oraison funèbre de Thomas Winter est marquée par l'empreinte du néo-stoïcisme ; l'œuvre-phare de ce courant, le De Constantia de Juste Lipse (1584), qui connut 80 éditions jusqu'au XVIII ${ }^{\mathrm{e}}$ siècle, " offrait aux citoyens l'arme des vertus stoïciennes pour se défendre contre les maux d'un monde constamment dévasté par les guerres, dans une Europe divisée par les rivalités confessionnelles ${ }^{172}$ ». Mais Juste Lipse est cité deux fois seulement ${ }^{173}$; Thomas Winter puise avant tout dans les Écritures et dans les sources antiques. À l'exégète jésuite Johannes Velazquez, il emprunte une formule qui résume sa vision du prince idéal, empreinte d'un stoïcisme christianisé :

Voici quel est le roi véritable, le plus riche de la grâce divine, le plus puissant, le plus parfait, le plus inébranlable dans son empire [...] : c'est sans aucun doute celui qui tolère et pardonne, avec force et douceur, les injures qui lui sont faites ${ }^{174}$.

L'accent est mis sur le contrôle des affects. La vertu, poussée, chez Léopold I Ir , jusqu'à l'héroïsme et même jusqu'à la sainteté, importe plus, aux yeux de Thomas Winter, que la majesté et l'habileté tactique ${ }^{175}$. Cette conception est radicalement opposée à celle de Machiavel et de ses émules. En affirmant que la douceur de Léopold I ${ }^{\text {er }}$ est en mesure de rivaliser avec la splendeur de Louis XIV, le jésuite Thomas Winter tente d'imposer un modèle de représentation princière fondé sur la pietas austriaca.

61 Au cœur de l'âge d'or des castra doloris impériaux (1654-1740), l'ensemble formé par l'oraison funèbre de Thomas Winter et par le "Temple de la Douceur" offre un exemple original de cohérence entre l'architecture et l'éloquence funèbre. Il invite l'auditoire à exercer sa curiosité, conformément à l'esthétique de l'«ingenium». Le recours à l'«ars symbolica » à des fins didactiques est caractéristique des jésuites et de leur spiritualité, qui accorde une place prépondérante à l'image. Celle-ci frappe davantage l'imagination que les discours ${ }^{176}$, comme l'écrit le jésuite Claude-François Ménestrier ${ }^{177}$. Selon Anné-Élisabeth Spica,

la fonction de l'emblématique est d'apporter un surcroît d'ornement, une « varietas " plaisante à l'œil autant qu'à l'esprit. La structure emblématique épouse tout en synthétisant la démonstration; elle illustre la brièveté dense comme l'élégance sobre du « nihil nimis », caractéristique d'une expression aboutie ${ }^{178}$. 
La représentation en trois dimensions doit donner plus de force persuasive et émotionnelle à l'éloge du prince. Dans l'argumentation, le monument funèbre fait office de preuve logique : comment ne pas croire à la douceur de Léopold $\mathrm{I}^{\mathrm{er}}$, puisqu'elle est représentée sous nos yeux! Dès lors que l'oraison funèbre tire ses arguments du castrum doloris, l'éloge devient tautologique et perd toute référence au réel. Le but est de renforcer le lien affectif entre les sujets et leur monarque, de créer une identité commune, de légitimer et de glorifier la dynastie, afin de rassembler les différentes parties de la Monarchie dans une mémoire unifiée.

\section{NOTES}

1. Issu d'une famille d'artistes tyroliens, Georg Anton Gumpp s'est formé en Italie et a été nommé architecte de la Cour à son retour. Cf. C. von WURZBACH, Biographisches Lexikon des Kaiserthums Österreich, Vienne, Kaiserlich-königliche Hof- und Staatsdruckerei, 1860, vol. 6, p. 32.

2. Cf. M. BRIX, Die Trauerdekorationen für die Habsburger in den Erblanden: Studien zur ephemeren Architektur des 16. bis 18. Jahrhunderts, diss., Kiel, 1971, catalogue, p. 154.

3. Constantia et Fortitudo Caroli Sexti [...], [Innsbruck], Michael Anton Wagner, [1740].

4. Cf. L. POPELKA, «Trauer-Prunk und Rede-Prunk. Der frühneuzeitliche Trauerapparat als rhetorische Leistung auf dem Weg zur virtuellen Realität », dans B. Boge et Ralf Georg Bogner éd., Oratio Funebris. Die katholische Leichenpredigt der frühen Neuzeit. Zwölf Studien. Mit einem Katalog deutschsprachiger katholischer Leichenpredigten in Einzeldrucken 1576-1799 aus den Beständen der Stiftsbibliothek Klosterneuburg und der Universitätsbibliothek Eichstätt, Amsterdam, Rodopi, 1999, p. 9-80.

5. Sur les funérailles des Habsbourg d'Autriche, voir B. BASTL et M. HENGERER, «Les funérailles impériales des Habsbourg d'Autriche, $\mathrm{XV}^{\mathrm{e}}-\mathrm{XVIII}^{\mathrm{e}}$ siècle ", dans J. A. Chrościcki, M. Hengerer et G. Sabatier éd., Les Funérailles princières en Europe XVI ${ }^{e}-\mathrm{XVIII} I^{e}$ siècle. 1. Le grand théâtre de la mort, Versailles, Paris, Centre de recherche du Château de Versailles et Éditions de la Maison des Sciences de l'Homme, 2012, p. 91-116; M. HENGERER, « The Funerals of the Habsburg Emperors in the Eighteenth Century ", dans M. Schaich éd., Monarchy and Religion. The Transformation of Royal Culture in Eighteenth-Century Europe, Oxford, Oxford University Press, 2007, p. 367-394 ; M. HAWLIKVAN DE WATER, Der schöne Tod: Zeremonialstrukturen des Wiener Hofes bei Tod und Begräbnis zwischen 1640 und 1740, Wien, Herder, 1989; «Der lezte Triumph. Das habsburgische Begräbniszeremoniell », dans K. VOCELKA et L. HELLER, Die Lebenswelt der Habsburger : Kultur- und Mentalitätsgeschichte einer Familie, Graz, Styria, 1997, p. 288-304.

6. Sur le cérémonial de Cour pour le deuil, l'enterrement et les obsèques, voir W. STANGL, Tod und Trauer bei den österreichischen Habsburgern 1740-1780, dargestellt im Spiegel des Hofzeremoniells, Saarbrücken, Südwestdeutscher Verlag für Hochschulschriften, 2010.

7. C. von WURZBACH, Biographisches Lexikon des Kaiserthums Österreich, Vienne, Kaiserlich-königliche Hof- und Staatsdruckerei, 1863, vol. 9, p. 384.

8. « Post Barcionem, Authore Leopoldo M[agno] fortiter propugnatam... ». Constantia et Fortitudo Caroli Sexti [...], [Innsbruck], Michael Anton Wagner, [1740], p. 2. Comprendre «Barcelonam » au lieu de «Barcionem ».

9. C'est ce que suggère M. BRIX, Die Trauerdekorationen für die Habsburger in den Erblanden, op. cit., catalogue, p. 153. 
10. $C f$. A. AuRnhammer et F. DÄUble, « Die Exequien für Karl V. in Augsburg, Brüssel und Bologna », dans P. R. Blum éd., Studien zur Thematik des Todes im 16. Jahrhundert, Wolfenbüttel, Herzog August Bibliothek, 1983, p. 141-190.

11. Sur le coût des obsèques impériales, voir P. DAUGA-CASAROTTO, «La pompe funèbre impériale dans la Monarchie habsbourgeoise entre baroque et Lumières (1705-1790) : ruptures et continuité des pratiques rituelles ", dans É. Pavy et F. Poulet éd., Contre le luxe, Paris, Garnier, à paraître en 2018.

12. B. DUHR, Geschichte der Jesuiten in den Ländern deutscher Zunge, Munich, Manz, 1928, vol. 2/1, p. 318-322.

13. Cf. J. WRBA, « Die österreichische Provinz der Gesellschaft Jesu im 16. und 17. Jahrhundert - in der Zeit des Barock», dans M. Benedikt éd., Verdrängter Humanismus, verzögerte Aufklärung, Klausen-Leopoldsdorf, Verlag Leben, Kunst, Wissenschaft, 1997, vol. 1/2, p. 277-321.

14. Cf. J. WRBA, « Der Orden der Gesellschaft Jesu im alten Universitätsviertel von Wien », dans G. Hamann éd., Das Alte Universitätsviertel in Wien 1385-1985, Vienne, Universitätsverlag, 1985, p. 56-57 ; B. DUHR, Geschichte der Jesuiten in den Ländern deutscher Zunge, op. cit., vol. 3, p. 190-194.

15. B. STOLLBERG-RILINGER, Maria Theresia : die Kaiserin in ihrer Zeit : eine Biographie, Munich, Beck, 2017, p. 218, 575.

16. "Horum quoque in partem Academicum hoc Societatis Jesu Collegium venire apprimè decuit : utpotè \& jam olim Augustissimae Caesarum Austriacorum familiae universim, \& nunc recens gloriosissimae recordationis Magno Leopoldo tot tamque ingentibus titulis devinctum, quos pro merito exsolvere quantiscunque impendiis nunquam possit." ANONYME, VENERATIO POSTHUMA Collegii CaesareoAcademici Societatis Jesu VIENNAE [...]. Nachschallender Ehren-Ruhm [...] LEOPOLDI I., Vienne, Johann Baptist Schönwetter, 1705, fol. A1 $\mathrm{r}^{\circ}$.

17. «Ein schuldigstes Denckmahl seiner unterthänigsten Danckbarkeit gegen diesen seeligst abgeleibten/ unsterblichen Tugend-Fürsten der Welt unter die Augen zu legen [...]; demselben [...] alle möglichste EhrBeweisungen/ wiewohl niemahlen zu Genügen/ abzustatten. » ANONYME, VENERATIO POSTHUMA Collegii Caesareo-Academici Societatis Jesu VIENNAE [...]. Nachschallender Ehren-Ruhm [...] LEOPOLDI I., op. cit., fol. A2 $\mathrm{v}^{\mathrm{o}}$.

18. On en trouvera une description dans M. BRIX, Die Trauerdekorationen für die Habsburger in den Erblanden, op. cit., catalogue, p. 85.

19. P. DAUGA-CASAROTTO, « Architecture éloquente et monuments de papier à la gloire de la "pietas austriaca". Une cérémonie funèbre en l'honneur de l'empereur Léopold ${ }^{\text {er }}$ de Habsbourg (Innsbruck, 1705) », dans C. Jérémie et M. Vénuat éd., L'Éloquence ecclésiastique de la pré-Réforme aux Lumières, Paris, Honoré Champion, 2015, p. 291-312 ; L. POPELKA, «Trauer-Prunk und RedePrunk. Der frühneuzeitliche Trauerapparat als rhetorische Leistung auf dem Weg zur virtuellen Realität », op. cit., p. 36 sq.

20. «Memento Domine David et omnis Mansuetudinis Ejus.» La Bible de Jérusalem traduit « mansuetudinis » par « labeur »; d'autres traductions donnent un sens analogue, mais il s'agit bien ici de la « douceur » de David.

21. Drey-mahl-seelige Sanfftmuth/ Ihro Römischen/ Kayserlichen/ auch zu Hungarn/ und Böhmen/ Königl. Majestät/ \&c. \&c. Leopoldi I. deß Grossen/ Mild-seeligst- und glorwürdigster Gedächtnuß ; Bey denen/ drey Täg nacheinander/ in der Kirche deß Kayserl. Profeß-Hauß der Gesellschaft Jesu am Hoff/ gehaltener Leich-Begängnussen/Oder/Seel- und Lob-Aemptern ; mit einer/ in drey Theil eingerichten/ Lob- und Trost-Predige/ Nach dem/ allda vorgestelten/ in drey-mahl-beseeligter Sanfftmuth/villfältig erleucht- und ansehentlichen Ehren-Gerüst/ von Thoma Winter, Der Gesellschaft JESU Priester/ und/ in obgemelter Kirche /durch die Fasten/ und Sonntäg/ gewöhnlichen Prediger/ zur schuldigsten EhrBeweisung geprysen. Gedruckt und verlegt/ zu Wienn/ bey Johann Jakob Kürner/ N. Oe. Land. Buchdr. 1705. 
22. Article «Höfische Rhetorik », in G. UEDING éd., Historisches Wörterbuch der Rhetorik, Tübingen, Niemeyer, 1992, vol. III, col. 1454 ; cf. également G. BRAUNGART, Hofberedsamkeit : Studien zur Praxis höfisch-politischer Rede im deutschen Territorialabsolutismus, Tübingen, Niemeyer, 1988.

23. P. ZOBERMAN, Les Cérémonies de la parole : l'éloquence d'apparat en France dans le dernier quart du XVII siècle, Paris, Honoré Champion, 1998, p. 11-12.

24. M. FOGEL, Les cérémonies de l'information dans la France du XVI au milieu du XVIII siècle, Paris, Fayard, 1989, p. 18-19.

25. "Quid, apud quem, pro quo, contra quem, quo tempore, quo loco, quo rerum statu, qua vulgi fama dicendum sit? " Quintilien, Institutio Oratoria, IV, 1, 52, trad. J. Cousin, Paris, Les Belles Lettres (C. U. F.). Cité par G. UEDING éd., Historisches Wörterbuch der Rhetorik, op. cit., vol. III, col. 137.

26. P. ZOBERMAN, Les Cérémonies de la parole, op. cit., p. 20.

27. W. PARAVICINI, «Von Materieller Attraktion, adligem Dienst und politischer Macht. Über den tiefen Sinn höfischer Lebensführung ", dans W. Paravicini éd., Luxus und Integration: materielle Hofkultur Westeuropas vom 12. bis zum 18. Jahrhundert, Munich, Oldenbourg, 2010, p. 273.

28. ARISTOTE, Rhétorique, III, chap. 7 et 12 ; CICÉRON, Orator, XXI, 70. Cf. art. "Angemessenheit », G. UEDING éd., Historisches Wörterbuch der Rhetorik, op. cit., vol. I, col. 579 sq.

29. «Auß unserer höchst verbundener Danck-Schuldigkeit ", dans T. WINTER, Drey-mahl-seelige Sanfftmuth [...] Leopoldi I. deß Grossen/ Mild-seeligst- und glorwürdigster Gedächtnuß [...], Innsbruck, Johann Jakob Kürner, 1705, p. 3.

30. De 1742 à 1745, Charles VII de Bavière occupa le trône du Saint Empire romain germanique.

31. C. REGIUS, Orator Christianus, Rome, 1612, p. 303 ; cf. P. DAUGA-CASAROTTO, "Oraison funèbre", dans A. Montandon et S. Neiva éd., Dictionnaire raisonné de la caducité des genres littéraires, Genève, Droz, 2014, p. 575-576.

32. En parlant des oraisons funèbres, Ledieu rapporte que Bossuet «n'aimait pas naturellement ce travail ». Cité par J. TRUCHET, «Introduction », dans Bossuet. Oraisons funèbres, Paris, Classiques Garnier, 1998, p. IV.

33. J. J. von eHRENFELD, Avgvstae Avgvsti Cordis Vigiliae Ferali Somno Svperiores, Et Infinitae, Das ist : Die von dem Todten-Schlaff unbesigte, Und nicht geendigte Wacht-barkeit CAROLI VI. [...] Durch eine LeichLob- Trost- und Sitten-Red kürtzlich entworffen [...], Augsbourg, Bernhardus Homodeus Mayer, 1740.

34. T. WINTER, Drey-mahl-seelige Sanfftmuth [...] Leopoldi I. deß Grossen/ Mild-seeligst- und glorwürdigster Gedächtnuß [...], op. cit., p. 3-6.

35. «Sondern [ ...] fast allein nur [...]/ damit wir nach der/ jetziger Zeit/ Weltgemeinen/ Klag- und HoffFarb/gleich gestaltet/ erschinen/ und darfür auch/ angesehen wurden. » Ibid., p. 4.

36. "Wiennerisches Uhr-Nest deren Römischen Adlern ", dans Ignaz REIFFENSTUEL, Daß Verwaißte/ getröste/ und unterwiesene Öesterreichische Schäflein, Vienne, Johann Georg Schlegel, 1711, fol. A4 r ${ }^{\circ}$. 37. Deux cérémonies de funérailles furent célébrées dans cette église : les obsèques officielles de la cour, et celles de la Confrérie des Morts, avec un castrum doloris sans doute modeste, puisqu'aucune gravure n'est parvenue jusqu'à nous.

38. «Vor allen aber /will [das Trauergerüst]/ die Göttliche Sanfftmuth selbst/ aller Welt offenbahr machen; indem dise/ mit reinem Silber-Gewülck umbgeben/ allhier/unter dem Oelbaum/als/einer schon bekannten Andeutung/ der Milde/ und Barmhertzigkeit/ dem Sanfftmüthigen Geist LEOPOLDI, von oben herab [...] die rechte Hand reichet ; mit der anderen aber Jhme ein/von gemeltem Oelbaum abgebrochenes Sträußlein/ in Gestalt eines Krantzs/ gleich bey erster Ankunfft auffzusetzen/ sich/[...] geneigt anerbietet. » T. WINTER, Drey-mahl-seelige Sanfftmuth [...] Leopoldi I. deß Grossen/ Mild-seeligst- und glorwürdigster Gedächtnuß [...], op. cit., p. 59.

39. Cf. M. BRIX, Die Trauerdekorationen für die Habsburger in den Erblanden, op. cit., catalogue, p. 85.

40. «Heureux les doux, car ils possèderont la terre. » $(M t .5,4$.

41. T. WINTER, Drey-mahl-seelige Sanfftmuth [...] Leopoldi I. deß Grossen/ Mild-seeligst- und glorwürdigster Gedächtnuß [...], op. cit., p. 7-8. 
42. C. A LAPIDE (C. van der Steen) : jésuite belge (1567-1637).

43. T. CAJETAN : théologien thomiste (1469-1534).

44. «Mais les humbles posséderont la terre, réjouis d'une grande paix.» Traduction : Bible de Jérusalem.

45. «Erster Theil für den Ersten Tag/ Drey-täger Leich-Begängnussen: Erste Erd-Besitzung Kayserlicher Sanfftmuth LEOPOLDI, in Erweitherung Seines Irrdischen Reichs/ und Vermehrung der Länder. Innhalt des Mittel-Schilds/ zu rechten Seithen [des castri doloris]: „Mansueti autem haereditabunt terram; \& delectabuntur in multitudine Pacis.“ Psalm. 36. V. 11. („Die Sanftmüthigen aber werden das Land erben ; und sich/ in grossen Friden/ erlustigen.") » T. WINTER, Drey-mahl-seelige Sanfftmuth [...] Leopoldi I. deß Grossen/ Mild-seeligst- und glorwürdigster Gedächtnu $\beta$ [...], op. cit., p. 8-26.

46. "Conduis tes affaires avec douceur, et tu seras plus aimé qu'un homme munificent.» Traduction : Bible de Jérusalem.

47. «Anderter Theil/ Für den Anderten Tag Drey-tägiger Leich-Begängnussen: Anderte Erd-Besitzung/ Kayserlicher Sanfftmuth LEOPOLDI ; in Einnehmung Menschlicher Hertzen. Innhalt deß Mittel-Schilds/ Zur Gegen-Seithen : „In Mansuetudine opera tua dirige ; \&, super hominum gloriam, diligêris.“ Eccli. 3. V. 19. „Verrichte deine Wercke mit Sanfftmüthigkeit: So wirst $\mathrm{Du} /$ neben dem/daß du Ehre bey denen Menschen hast/ auch geliebet werden.“” T. WINTER, Drey-mahl-seelige Sanfftmuth [...] Leopoldi I. deß Grossen/ Mild-seeligst- und glorwürdigster Gedächtnuß [...], op. cit., p. 26-57.

48. "Yahvé soutient les humbles, jusqu'à terre il abaisse les impies." Traduction: Bible de Jérusalem.

49. «Dritter Theil. Für den dritten Tag der Leich-Begängnussen ; [...] Dritte Erd-Besitzung/ Der Sanfftmuth LEOPOLDI, In Erlangung de $\beta$ Himmlischen Paradey $\beta$. Innhalt de $\beta$ Mittel-Schilds/Gegen dem Hoch-Altar: „Suspiciens Mansuetos Dominus: Humilians autem peccatores, usque ad Terram.“ Psal. 146. V. 6. «Der Herr nimmet die Sanfftmüthigen auff: Aber die Sünder demüthiget er/ bi zur Erden. » T. WINTER, Drey-mahl-seelige Sanfftmuth [...] Leopoldi I. deß Grossen/ Mild-seeligst- und glorwürdigster Gedächtnuß [...], op. cit., p. 57-79.

50. Notamment Gelasius HIEBER, APOTHEOSIS LEOPOLDI PRIMI CAESARIS, Das ist: DargeLegte HeILIgkeIt KaIsers LeopoLDI Des Ersten [...] In dem Hoch-adelich-gefreyten weltlichen Reichs-Stifft Obermünster/ [...] Bey Solennen Exequien [...] Sammt einer nothwendig-beyligenden Schutz-Schrifft, Ratisbonne, Johann Georg Hoffmann, 1705.

51. Thomas DUELLER, Österreichischer Phoenix oder Ferdinandus Quartus [...], Vienne, Matthias Cosmerovius, 1654 .

52. Cf. L. POPELKA, "Trauer-Prunk und Rede-Prunk. Der frühneuzeitliche Trauerapparat als rhetorische Leistung auf dem Weg zur virtuellen Realität », op. cit., p. 45.

53. Christoph TRAUT, Ferdinandi des Dritten [...] Gottseeligkeit/ in Vergleichung mit dem grossen Adler Ezechielis, welcher das Marck deß Ceder-Baums genommen [...], [Vienne], Matthaeus Cosmerovius, 1657. Le sens de cette allégorie est précisé dans l'exorde, fol. A2 $\mathrm{r}^{\circ}-\mathrm{A} 3 \mathrm{r}^{\circ}$.

54. « Aldrovand. Ornith. I, 2 col. 56 ». Ibid., fol. E3 vº. Ulisse Aldrovandi (1522-1605), naturaliste de Bologne, auteur de cette Ornithologiae parue en 1645, et de plusieurs autres ouvrages sur la faune, servit de source à l'emblématique. Voir Thesaurus eruditionis, URL: http://www.hab.de/en/home/ research/projects/thesaurus-eruditionis.html. Sur les sources de l'emblématique, voir F. VUILleUMier, La Raison des figures symboliques à la Renaissance et à l'âge classique: études sur les fondements philosophiques, théologiques et rhétoriques de l'image, Genève, Droz, 2000.

55. «Bey blinder Heyden-schafft war der brauch/ daß sie nach dem Todt eines verstorbnen Kayser/ ein EhrnGerist von gelegten Holtz auffrichteten/in Form eines Tabernackl/al $\beta$ von vnten weiter/von oben am Gipfl allzeit enger zusamme gehendt: solchen formierten sie/ alß hätte er drey Staffl/ oder Grad; diesen behenckten sie vnd zierten mit Helffenbain/mit gemahlten Taffeln vnd Bildnussen/mit Kriegszaichen vnd Waffen/mit Silber und Gold/ mit dem besten Rauchwerck angesteckt. In diesem legten sie das Contrafe des Kaysers auff einen Rott-scharlachenem Teppich/ auff den Gipfl stellten sie ein lebendigen Adler. Dises also 
bestellte Todten vnd EhrnGerist zünden sie mit Facklen an/ darauff der Adler sich in die Lufft erschwinget/ vnd gantz von den Augen der ansehenden entziehet/der Meynung/ daß die Glorwürdige Seel des Kaysers also in dem Himmel vnter die Versamblung vnd Gesellschaft der Götter zur vnsterbligkeit sich auffschwinge. » C. TRAUT, Ferdinandi des Dritten [...] Gottseeligkeit/ in Vergleichung mit dem grossen Adler Ezechielis, welcher das Marck deß Ceder-Baums genommen [...], op. cit., fol. E3 $\mathrm{v}^{\mathrm{o}}-\mathrm{E} 4 \mathrm{r}^{\mathrm{o}}$.

56. «Dises ist ein Gedicht vnd lauter Betrug der blinden Haydenschafft. Dann was wollen die abgötische Kayser/ die nur ein scheinende vnd vermeinte Religion [...] hätten/zur Vnsterbligkeit auffgehoben werden? Allein die wahre Religion der Christlichen Kayser/ vnd deß Rechten Eintzigen GOTT Verehrung macht vnsterblich. » Ibid., fol. E4 $\mathrm{r}^{\mathrm{o}}-\mathrm{E} 4 \mathrm{v}^{\mathrm{o}}$.

57. "Aller/ massen dann vnser Allergnädigster Kayser Ihme ein solches Ehrngerist auffgerichtet/ bestehend von der Dreyfachen Pietät [...] gegen den Heiligen Gottes/ gegen der Himmels-Königin/ vnnd gegen den Allmächtigen GOTT selbst. Dises Ehrngerist hat seine Mayestät mit dem hellen Silber seiner Freundligkeit/ mit dem Helffenbein seiner Weiß- vnd Klugheit/ mit dem Goldt seiner Freugebigkeit [...] geziert [...]. Auß diesem Ihme also zugerichten Ehrn vnd Todtengestell hat sich FERDINANDI Gottehrende Seel als ein Adler auffgeschwungen in das Orth aller Christlichen vnd Gottseeligen Hälden/ in das Orth der Vnsterbligkeit. »Id.

58. M. BRIX, Die Trauerdekorationen für die Habsburger in den Erblanden, op. cit., catalogue, p. 53.

59. Cf. F. POLLERoss, "Der Globus als Herrschaftssymbol der Habsburger », dans W. Krömer éd., 1492-1992: Spanien, Österreich und Iberoamerika. Akten des 7. Spanisch-Österreichischen Symposions, Innsbruck, Verlag des Instituts für Sprachwissenschaft der Universität Innsbruck, 1993, p. 35-50.

60. M. BRIX, Die Trauerdekorationen für die Habsburger in den Erblanden, op. cit., catalogue, p. 53.

61. Ibid., catalogue, p. 98.

62. Johann KUGLER, Parelion Academicum, Sive Augustissimus Imperator Leopoldus, Sole duplo, Sapientiâ \& Sanctitate Jllustris [...], Breslau/ Wrocław, Johannes Jankius, [1705]; soit, en français, Parhélie académique : Léopold I ${ }^{\text {er }}$, double soleil, illustre par sa sagesse et sa sainteté.

63. Voir la description de l'appareil funèbre dans Parelium Leopoldinum; Sive Leopoldus [...], Augustissimi Nominis Sui Anagrammatismo Sol Duplus In Ortu, Duplus In Progressu, Duplus In Occasu ; [...] Collegio Wratislaviensi Soc. Jesu, \& Ejusdem Universitate Leopoldina [...] Luctuosissimè Deploratus [...], Breslau/ Wrocław, Johannes Jankius, [1705]. Un parhélie, également appelé « soleil double », est un phénomène optique consistant en l'apparition de deux répliques de l'image du soleil, placées horizontalement de part et d'autre de celui-ci. Voir L. POPELKA, « Trauer-Prunk und Rede-Prunk. Der frühneuzeitliche Trauerapparat als rhetorische Leistung auf dem Weg zur virtuellen Realität », op. cit., p. 47-49.

64. Andreas SAX, Leopoldus der Erste und Grosse [...], Brünn/ Brno, Georg Strnadt, 1705.

65. Voir Anton WALTER, Schrifft-mässiger höchster Ehren-Flug Der Himmlischen Reichs-Adler [...], Ratisbonne, J. Egidius, 1705 ; voir L. POPELKA, «Trauer-Prunk und Rede-Prunk. Der frühneuzeitliche Trauerapparat als rhetorische Leistung auf dem Weg zur virtuellen Realität », op. cit., p. 45.

66. Voir Johann Baptist comAzZI, Ad Sodales Hispanae Confraternitatis SS. Sacramenti [...], Oratio Panegyrica [...], Vienne, Johann Van Ghelen, 1705.

67. Voir l'ouvrage du jésuite français C.-F. MÉNESTRIER, Des décorations funèbres, où il est amplement traité des tentures, des lumières, des mausolées, catafalques, inscriptions et autres ornemens funèbres, Paris, De la Caille, 1683.

68. Pius MANZADOR, Ehren- und Trauer-Rede [...] In der Kaiserl. Hof-Pfarr-Kirchen zu St. Michael in Wien [...], Vienne, Johann Peter v. Gehlen, $1741 ; c f$. M. BRIX, Die Trauerdekorationen für die Habsburger in den Erblanden, op. cit., catalogue, p. 150.

69. P. DAUGA-CASAROTTO, «La pompe funèbre impériale dans la Monarchie habsbourgeoise entre baroque et Lumières (1705-1790) : ruptures et continuité des pratiques rituelles », op. cit. 
70. «Imgleichen wird auch/ durch so Liecht-reichen Schein/ diser in grosse Anzahl brinnenden Kertzen/ und Feuer-Flammen/ nichts anderes angedeutet; als/ daß/ bey Außschliessung aller Trübe/ und Betrübnu $\beta /$ hellscheinende Hoffnung in aller Glaubigen Hertzen/ angezündet werden solle : daß nunmehr/vor dem Angesicht de $\beta$ Vatters der Liechter/gewüntschte Bescheinung de $\beta$ ewigen Liechts dem Jenigen verlyhen seye ; dessen gantzer Lebens-Schein/ vom Ein- oder Auffgang/ bi zum Au $\beta$ - oder Untergang/ jederzeit/ gleich dem grossen Welt-Liecht/ der Sonne/ geleuchtet hat. " (T. WINTER, Drey-mahl-seelige Sanfftmuth [...] Leopoldi I. deß Grossen/ Mild-seeligst- und glorwürdigster Gedächtnuß [...], op. cit., p. 4-5).

71. L. POPELKA, «Trauer-Prunk und Rede-Prunk. Der frühneuzeitliche Trauerapparat als rhetorische Leistung auf dem Weg zur virtuellen Realität », op. cit., p. 13.

72. «Was hätte dann sollen/ oder können/ zum Lob- und Trost/ vortrefflicher ersinnet/ und/ mit schon angedeuter/Lob- und Trostpredige/ zuerweisen/vorgenommen werden? Als/ was im gegenwärthigen/ villfälltig erleichten Ehren-Gerüst vorgestellet/ und angesehen wird: Die Drey-mahl-Seelige Sanfftmuth LEOPOLDI. » (T. WINTER, Drey-mahl-seelige Sanfftmuth [...] Leopoldi I. deß Grossen/ Mild-seeligst- und glorwürdigster Gedächtnuß [...], op. cit., p. 8).

73. «Und dises ist : warumben gegenwärtiges [...] Ehren-Gerüst/ mit einer/ also ansehentlichen Cron/ von oben herab/gezieret worden. » Ibid., p. 78.

74. «Weilen aber das Lob- und Ehren-Werck/ nunmehr/ biß zur Cron/ und/ endlichen Seeligkeit LEOPOLDI, gebracht worden; so wills sich gebühren; da $\beta$ sich meine Lob-und Ehren-Rede auch zum Schlu $\beta$ -Ende begebe. »Ibid., p 78-79.

75. Voir M. FUMAROLI, L'Âge de l'éloquence : rhétorique et "res literaria ", de la Renaissance au seuil de l'époque classique, Genève, Droz, 1980, p. 233 sq., deuxième partie : «Du multiple à l'un : les styles jésuites »; B. BAUER, Jesuitische " ars rhetorica » im Zeitalter der Glaubenskämpfe, Francfort/M. et New York, Peter Lang, 1986 ; voir également A.-É. SPICA, « Les jésuites et l'emblématique », op. cit., p. 647 ; P. DAUGA-CASAROTTO, «La pompe funèbre impériale dans la Monarchie habsbourgeoise entre baroque et Lumières (1705-1790) : ruptures et continuité des pratiques rituelles », op. cit.

76. «Was ich dann von unserem [...] Landes-Herrn zu reden [habe], weisen mir die gegenwärtiges TrauerGerüst auszierende Tugend-Bilder. " Liborius À SANCTA BARBARA, Das grosse Tugend-Hertz Carl des Sechsten [...], Vienne, Johann Ignaz Heyinger, 1740, p. 6.

77. A.-É. SPICA, « Les jésuites et l'emblématique », op. cit., p. 635.

78. Ibid., p. 634

79. Ibid., p. 638.

80. Id.

81. Sur l'emblématique dans l'art funèbre, voir L. POPELKA, «Trauer-Prunk und Rede-Prunk. Der frühneuzeitliche Trauerapparat als rhetorische Leistung auf dem Weg zur virtuellen Realität ", op. cit., p. 16-23.

82. Cf. G. OESTREICH et N. MOUT, Antiker Geist und moderner Staat bei Justus Lipsius (1547-1606) : der Neustoizismus als politische Bewegung, Göttingen, Vandenhoeck \& Ruprecht, 1989, p. 62.

83. ANONYME, Princeps in compendio, hoc est puncta aliquot compendiosa, quae circa gubernationem rei publicae observanda videntur, Vienne, Gelbhaar, 1632 ; voir K. REPGEN, Das Herrscherbild im 17. Jahrhundert, Münster, Aschendorff, 1991, p. 79-104 ; H. STURMBERGER, « Der habsburgische "Princeps in compendio" und sein Fürstenbild », dans H. Sturmberger éd., Land ob der Enns und Österreich : Aufsätze und Vorträge, Linz, Oberösterreichisches Landesarchiv, 1979, p. 188-210 ; A. CORETH, Pietas Austriaca: Ursprung und Entwicklung barocker Frömmigkeit in Österreich, Vienne, Verlag für Geschichte und Politik, 1959, p. 9-13.

84. G. LAMORMAIN, Ferdinandi II Romanorum Imperatoris Virtutes, Vienne, Gelbhaar, 1638.

85. Philibert boccabella, Hauß der Weisheit Von Siben Säulen/ Daß ist [...] FERDINANDI Deß Dritten/ Sibenfache/ Kayserliche/ vnnd nach Christ-mildesten Ableben Noch Lebende Tugendt [...], Vienne, Matthäus Cosmerovius, 1657. 
86. G. HIEBER, APOTHEOSIS LEOPOLDI PRIMI CAESARIS, Das ist: DargeLegte HeILIgkeIt KaIsers LeopoLDI Des Ersten [...] In dem Hoch-adelich-gefreyten weltlichen Reichs-Stifft Obermünster/ [...] Bey Solennen Exequien [...] Sammt einer nothwendig-beyligenden Schutz-Schrifft, op. cit.

87. I. REIFFENSTUEL, Wunder-voller Adlers-Flug Zur Göttlichen Sonne in Himmel. Das ist Glor-würdigiste Lob- Ehren- und Groß-Thaten Weylands LEOPOLDI [...] des Ersten [...] In Einer Deutschen Zier-Rede Vorgetragen [...], Vienne, Johann Baptist Schönwetter, 1705; Anton WALTER, Schrifft-mässiger höchster Ehren-Flug Der Himmlischen Reichs-Adler [...], op. cit. ; Ferdinand WIDMAN, Morgen-Stern bey der Sonne. Der Kaiser mit Gott. Das ist : LEOPOLD Der Erste [...] Lebte mit GOtt/ sturbe in GOtt/ Jn MittagSchein Kayserlichen Tugenden erloschen [...], Vienne, Cosmerovische Erben, 1705 ; Albert PREZ, Das GottseLIge RegIeren/ LehrreIChe ErMahnen/ frVtzeItIge Hinfahren/ Des In dem Alt-Testamentischen Gottseligen König Josaphat vorgestellten [...] JOSEPHI [...] des Ersten/ [...] Durch gegenwärtige Leich und Lob-Predig/ in der Käys. Stiffts-Kirchen als S. Bartholomaeum in Franckfurt/[...] vorgetragen, Francfort/ M., Johann Bauer, 1711.

88. Franz MERSCH, Carl Dieses Nahmens Der Sechste Römischer Kayser FORTITUDINE, \& CONSTANTIA Durch Stärcke, und Standhafftigkeit, Ob beeden Ein doppelt glorreicher Kayser, bey gehaltenem LeichGepräng Für höchstgemeldten Gottseeligen Monarch In Academischer Kirch der Gesellschafft JESU zu Breßlau [...], Breslau/ Wrocław, Academische Buchdruckerey, 1740; Leopold FISCHER, Die In dem Himmel gecrönte Stärcke, und Standhaftigkeit, Carls des VI. [...] Welche sich Groß in dem Glück, Noch grösser im Unglück, Am grösten im Tod gezeiget hat [...], Linz, Johann Michael Feichtinger, 1740.

89. I. REIFFENSTUEL, Reichs-Herrschende Bild-Saule/ Auß Gold/ und Silber/ Ertz und Eisen/ Zu Staub der Erden zermalet. Das ist : Betrübtester Todtsfahl Ihro Römisch Kayserlichen [...] Majestät [...] JOSEPHI I, Vienne, Andreas Heyinger, 1711.

90. Sur l'éloquence ingénieuse, voir notamment M. FUMAROLI, L'Âge de l'éloquence, op.cit., p. 202-222 ; F. VUILleUmier, «Les conceptismes ", dans M. Fumaroli éd., Histoire de la rhétorique dans l'Europe moderne, Paris, PUF, 1999, p.517-537; M. BLANCO, Les Rhétoriques de la Pointe: Baltasar Gracián et le Conceptisme en Europe, Paris, Honoré Champion, 1992.

91. Die Bey dem Gott-seeligen Hintritt Leopolds des Ersten/ [...] Auffwartende Adler: Oder das TodtenGerüste/ Welches zu Begehung der herrlichen Exequien [...] In der Augustiner Hoff-Kirchen bey der Loretten-Capell auffgerichtet/ Und von Johann Luca Hyldebrand/[...] mit vier in Kupffer gestochenen Rissen so wohl von dem Gerüste an sich /als denen dabey in der Kirchen auffgemachten Sinnen-Bildern und darunter gestandenen Schrifften vorgestellet/ Und jetzo mit einer deütlichen Beschreibung [...] an das Licht hervor gegeben worden [...], Vienne, Andreas Heyinger, 1705, fol. B1 $\mathrm{r}^{\circ}$.

92. F. VUILLEUMIER, « Les conceptismes », op. cit., p. 528.

93. J. MASEN, Ars nova argutiarum, Cologne, J. Kinckius, 1649 ; sur Jacob Masen, voir J.-M. valentin, Les Jésuites et le théâtre (1554-1680) : contribution à l'histoire culturelle du monde catholique dans le SaintEmpire romain germanique, Paris, Desjonquères, 2001, p. 135-144, 577-599.

94. J. KNAPE, art. «Barock », dans G. UEDING éd., Historisches Wörterbuch der Rhetorik, op. cit., vol. I, col. 1287.

95. B. BAUER, Jesuitische « ars rhetorica » im Zeitalter der Glaubenskämpfe, op. cit., p. 462.

96. «[...] Deren Welt-Menschen Urtheil (welches/ aller zeitlichen Glückseeligkeit Grund-Veste/ nicht in die Tugend/ sondern/ in jhre/ eytle/ Wanckelbahre/ Staats-Meynungen/ setzet. » T. WINTER, Drey-mahlseelige Sanfftmuth [...] Leopoldi I. deß Grossen/ Mild-seeligst- und glorwürdigster Gedächtnuß [...], op. cit., p. 7.

97. R. BIRELEY, The Counter-Reformation Prince: Anti-Machiavellianism or Catholic Statecraft in Early Modern Europe, Chapel Hill, University of North Carolina Press, 1990, p. 136 ; J.-M. VALENTIN, Le Théâtre des Jésuites dans les pays de langue allemande, op. cit., p. 145-148, 161-176.

98. R. BIRELEY, The Counter-Reformation Prince, op. cit., p. 142.

99. « Nach deren Welt-Menschen Urtheil [...] haltet man darfür : Ein Sanfftmüthiger verliehre/ durch sein Süsse/ und Mildigkeit/Cron/ und Scepter/Länder/ und Königreich. In der Sach selbst aber ist dises/ also 
weith davon; daß derselbe viellmehr/alles/ was auch schon entgangen ist/ widerumb eroberet/ und mit grossem Zusatz vermehret/ durch die Sanfftmuth besitzet. » T. WINTER, Drey-mahl-seelige Sanfftmuth [...] Leopoldi I. deß Grossen/ Mild-seeligst- und glorwürdigster Gedächtnuß [...], op. cit., p. 7.

100. «Die falsche und verschlagene Politica». G. LAMORMAIN, Ferdinandi II Romanorum Imperatoris Virtutes, op. cit.; cité par H. STURMBERGER, "Der habsburgische "Princeps in compendio" und sein Fürstenbild», op. cit., p. 204.

101. "Hoffentlich wird sothanem Vortrag niemand wider-sinnig seyn/ mit der Einbildung; als wäre solcher vill zu schlecht/ zum Lob/ und Ruhm/ höchster Welt-Würde [...].» T. WINTER, Drey-mahl-seelige Sanfftmuth [...] Leopoldi I. deß Grossen/ Mild-seeligst- und glorwürdigster Gedächtnu $\beta$ [...], op. cit., p. 9.

102. Rhéteur et commentateur aristotélicien (317-388).

103. "So soll auch Niemand in jene Irr-Meynung gerathen; als geschähe dem grossen Inhalt/ und LebensBild aller Tugenden/ LEOPOLDO, ungemeine Unbild: indem/ allein in seine Sanfftmuth/ [...] aller anderer seiner willfältigen Tugenden/Preyß-werthiste Thatten zusamb gezohen/ und gleichsamb/ unterdrucket werden.» T. WINTER, Drey-mahl-seelige Sanfftmuth [...] Leopoldi I. deß Grossen/ Mild-seeligst- und glorwürdigster Gedächtnuß [...], op. cit., p. 9.

104. «Eines Sinn-reichen Verstandts kennbahrer Beweis ists: De $\beta$ Kaysers/ fast unendliche Tugenden/ also wissen/zusamm zubringen/oder einzuschliessen : Damit die allzuschwache Beredenheit/vom Uberflu $\beta$ Prey $\beta$-würdigster Geschichten/ nicht außgeschöpffet/ und überwunden werde. », ibid., p. 10.

105. «[Eine] vollkommene Beherrschung aller natürlichen Gemüths-Bewegungen », ibid., p. 11.

106. "Schrockenbahre Tugend », ibid., p. 15.

107. « Maechtiger/ als alle Kriegs-Lüst/ und geheime Streitt-Kuensten », ibid., p. 15.

108. Ibid., p. 15, 18-21.

109. Ibid., p. 19 sqq.

110. J. schumann, Die andere Sonne: Kaiserbild und Medienstrategien im Zeitalter Leopolds I., Berlin, Akademie Verlag, 2003, p. 185.

111. Voir la comparaison entre les représentations de Léopold $\mathrm{I}^{\mathrm{er}}$ et de Louis XIV (ibid., p. 208-209).

112. Voir M. WREDE, «Türkenkrieger, Türkensieger. Leopold I. und Ludwig XIV. als Retter und Ritter der Christenheit ", dans C. Kampmann éd., Bourbon, Habsburg, Oranien: konkurrierende Modelle im dynastischen Europa um 1700, Cologne, Böhlau, 2008, p. 151-152.

113. T. WINTER, Drey-mahl-seelige Sanfftmuth [...] Leopoldi I. deß Grossen/ Mild-seeligst- und glorwürdigster Gedächtnuß [...], op. cit., p. 22.

114. Ibid., p. 23.

115. G. LAMORMAIN, Ferdinandi II Romanorum Imperatoris Virtutes, op. cit.

116. Cf. T. WINKELBAUER, Ständefreiheit und Fürstenmacht: Länder und Untertanen des Hauses Habsburg im konfessionellen Zeitalter, Vienne, Ueberreuter, 2003, vol. 1, p. 62.

117. " [Es wurde] von vielen behauptet, Christus habe aus einem Crucifix mit Ferdinand geredet, und gesagt, er solle guten Muth und Vertrauen haben. "Guillaume Lamormain, Ferdinand II. Ein Tugendspiegel für alle Stände, Vienne, Ueberreuter, 1857, p. 10.

118. " Je ne t'abandonnerai pas. »

119. Cf. K. MALETTKE, Les Relations entre la France et le Saint-Empire au XVII ${ }^{e}$ siècle, Paris, Champion, 2001 ; K. MALETTKE, Frankreich, Deutschland und Europa im 17. und 18. Jahrhundert: Beiträge zum Einfluss französischer politischer Theorie, Verfassung und Außenpolitik in der Frühen Neuzeit, Marburg, Hitzeroth, 1994.

120. F. MATSCHE, Die Kunst im Dienst der Staatsidee Kaiser Karls VI: Ikonographie, Ikonologie und Programmatik des « Kaiserstils », Berlin, New York, De Gruyter, 1981, vol 1, p. 4.

121. T. WINKELBAUER, Ständefreiheit und Fürstenmacht, op. cit., vol. 1, p. 363.

122. Parmi une abondante bibliographie, on peut citer : J. schumann, Die andere Sonne, op. cit.; J. SCHILLINGER, Les Pamphlétaires allemands et la France de Louis XIV, Berne et al., Peter Lang, 1999 ; 0. 
CHALINE, «Ludwig XIV. und Leopold I. als Herrscher. Mythos oder Wirklichkeit des absoluten Fürstentums?", dans H. Neuhaus éd., Die Frühe Neuzeit als Epoche, Munich, Oldenbourg, 2009, p. 35-50; C. KAMPMANN éd., Bourbon, Habsburg, Oranien: konkurrierende Modelle im dynastischen Europa um 1700, Cologne, Böhlau, 2008 ; M. WREDE, « Frankreich, das Reich und die deutsche Nation im 17. und 18. Jahrhundert. Wahrnehmungsmuster und Wahrnehmungswandel», dans E. Leuschner, T. Wünsch et G. Schmidt éd., Die deutsche Nation im frühneuzeitlichen Europa. Politische Ordnung und kulturelle Identität, Munich, Oldenbourg, 2010, p. 157-177.

123. J. CORNETTE, Le Roi de guerre. Essai sur la souveraineté dans la France du Grand Siècle, Paris, Payot \& Rivages, 2010, p. 270.

124. Sur la campagne des statues, voir P. BURKE, Louis XIV: les stratégies de la gloire, Paris, Seuil, 1995, p. 99 sq.

125. Cf. A. CORETH, Pietas Austriaca, op. cit.; J. BÉRENGER, « Pietas austriaca. Contribution à l'étude de la sensibilité religieuse des Habsbourg », dans J.-P. Bardet et M. Foisil éd., La Vie, la mort, la foi, le temps. Mélanges offerts à Pierre Chaunu, Paris, PUF, 1993, p. 403-421.

126. $C f$. T. BROCKMANN, « Das Bild des Hauses Habsburg in der dynastischen Historiographie um 1700 », dans C. Kampmann éd., Bourbon, Habsburg, Oranien : konkurrierende Modelle im dynastischen Europa um 1700, Cologne, Böhlau, 2008, p. 41.

127. «Alt-Oesterreichisches Gemüt», T. WINTER, Drey-mahl-seelige Sanfftmuth [...] Leopoldi I. deß Grossen/ Mild-seeligst- und glorwürdigster Gedächtnuß [...], op. cit., p. 33.

128. "Imago Dei per omnia », ibid., p. 35-40.

129. J. BÉRENGER, Histoire de l'empire des Habsbourg : 1273-1918, Paris, Fayard, 1990, p. 335-341.

130. Ibid., p. 335.

131. Ibid., p. 343.

132. Cf. ibid., p. 341-348 et 355-356 ; J. P. SPIELMAN, Leopold I. Zur Macht nicht geboren, Graz, Vienne, Cologne, Styria, 1981, p. 60-71.

133. J. P. SPIELMAN, Leopold I. Zur Macht nicht geboren., op. cit., p. 68.

134. Ibid., p. 70.

135. J. schumann, Die andere Sonne, op. cit., p. 128.

136. Cf. ibid., p. 118-128.

137. T. WINTER, Drey-mahl-seelige Sanfftmuth [...] Leopoldi I. deß Grossen/ Mild-seeligst- und glorwürdigster Gedächtnuß [...], op. cit., p. 31.

138. "Welches alles/ dem mildisten Hertzen/ Unsers Allerweisisten Herrens/ also unverwendlich eingedruckt war: daß er/in endlich/gleichsamb noth-gezwungener/ und/ unverantwortliche-befundener/ Loß- und Freysprechung/ verurtheilter Ubeltätter/ jedoch seine Gnad-Willigkeit/ wenigist/ durch Milderung bestimbter Todt-Peynen/ hat erweisen wollen : nebst Abschaffung jener grausamen Quälen/ und Plagen; durch welche die armen Sünder/ langwührig gepeyniget/ in Gefahr ihrer Seelen-Heyls gerathen möchten. Man könnte ja billich von unserem Augustissimo schreiben/ was von Augusto dem Kayser/ Seneca/ der Nach-Welt gegeben: Augustum, dare poenas, apparebat ; quoties exigebat. » Thomas Winter, op. cit., p. 35. La citation empruntée par Winter au De Clementia (I, X) réécrit le texte de Sénèque, qui est «[...] quod dare illum poenas apparebat, cum exigeret. » (De la Clémence, I, 10, 3, éd. Fr.-R. Chaumartin, Paris, Les Belles Lettres, C. U. F., 2005, p. 20).

139. T. WINTER, Drey-mahl-seelige Sanfftmuth [...] Leopoldi I. deß Grossen/ Mild-seeligst- und glorwürdigster Gedächtnuß [...], op. cit., p. 35.

140. «[...] welche/vom Schwerdt zu erretten/ jhme nicht mehr gäntzlich frey stunde. »Id.

141. "[...] Daß jhre Schuld/ keines weegs/ auch auff jhre Hinterlassene gezohen [...] werden : obschon einige Eyferer strengerer Gerechtigkeit/ den mildisten Kayser dahin zu vermögen gesuchet; alle Erben gedachter Todt-Schuldigen/ jhres Adel-Thums entsetzet/ in allgemeinen Hauffen/ und/ jederzeit Verächtliches Unangesehen/ zu verstossen. »Ibid., p. 36. Sur la clémence dont fit preuve Léopold I ${ }^{\text {er }}$ 
lors de la conjuration des magnats hongrois, $c f$. J. P. SPIELMAN, Leopold I. Zur Macht nicht geboren., op. cit., p. 63-67.

142. Cf. J. BÉRENGER, Histoire de l'empire des Habsbourg, op. cit., p. 346 ; J. P. SPIELMAN, Leopold I. Zur Macht nicht geboren., op. cit., p. 69.

143. «Es gezimme sich nicht/ einer Kayserlichen Majestät; seine offene Feind (welche mit Kriegs-Vewalt zuverfolgen/ und anderst nicht/ wann sie auch in die Händ kommen/ als durch offentliche GerichtsStraff// ihres Meyneids halber/ anderen zum Schrocken/ hinzurichten seynd) durch geheime Nachstellungen/ mit Gifft/ oder anderen/ gleich-schädlichen/ und/ einem Welt-Fürsten/ un-anständigen/ mehr/ Rach-als/Straff/ scheinenden Mitteln/ ohne Belaydigung selbst-eigener hocher Würde/ in welcher Gottes Gewalt über die Welt angesehen wird/ umb das Leben zubringen. »Ibid., p. 37.

144. Ibid., p. 32-40.

145. "Nicht bewegt werden/ von gemeinen Klag- und Schmach-Reden/ zur Ungedult; sondern/ in Anhörung derselben/ unverwirrte/ Mild- und Sanfftmüthigkeit erzeigen. »Ibid., p. 41.

146. Ibid., p. 42.

147. « Die Stäffeln der Sanfftmuth/ durch welche man auch/zur verheissenen Seeligkeit gelanget/ welche darau $\beta$ zufolgen pflegt/ seynd: 1. Mit sanfftmüthigem Hertzen/ und Mund/ gegen jedermann sich freundlich erweisen. 2. Deß Nächsten Zorn/ Mit Sanfftt- und gantz gütiger Antwort begegnen. 3. Zugefügte Unbilden/ und Beraubungen/ ohne Anzeigen einiger Beleydigung/ still/ und sittsam übertragen. 4. In sothanen Begebenheiten/ auch einige Freud erweisen. 5. Feindliche Boßhafftigkeit/ und Grimen/ durch Sanfftmuth/ und Gutthätigkeit überwünden; auch/ [...] auß Feind/ Freund/ zumachen/ sich/ so vill möglich ist/ befleissen. » Ibid., p. 43.

148. De Vita Agricolae (cité « Tacitus in Agricult. »). Ibid., p. 40.

149. J. velazQueZ sJ, In Psalmum Davidis Centesimum Commentarij, Litterales \& Morales; Sive De Optimo Principe Et Optimo Principis Administro. Libri Quinque [...], Anvers, Meursius, 1640. Cf. Thesaurus Eruditionis, Herzog-August-Bibliothek Wolfenbüttel ; http://www.hab.de/en/home/research/ projects/thesaurus-eruditionis.html.

150. G. SANCHEZ : jésuite espagnol (1554-1628).

151. L. DE GRENADE : dominicain espagnol (1504-1588).

152. T. WINTER, Drey-mahl-seelige Sanfftmuth [...] Leopoldi I. deß Grossen/ Mild-seeligst- und glorwürdigster Gedächtnuß [...], op. cit., p. 46-50.

153. « Lasset doch/ ungehinderet/ die Armen zu mir kommen [...]. » Ibid., p. 51.

154. "Lasset doch/ umb Gottes Willen/ alle Menschen/ die meiner verlangen/ vor mich kommen. Dann/ ich bin ja darumb nicht zum Regiment beruffen worden; Damit ich in einem Drühelein eingeschlossen seyn sollte. »Id.

155. O. CHALINE, « Ludwig XIV. und Kaiser Leopold I. als Herrscher. Mythos oder Wirklichkeit des absoluten Fürstentums ? », dans H. Neuhaus éd., Die Frühe Neuzeit als Epoche, Munich, Oldenbourg, 2009, p. 39 ; cf. également M. WREDE, «Türkenkrieger, Türkensieger. Leopold I. und Ludwig XIV. als Retter und Ritter der Christenheit », op. cit., p. 158.

156. «Ich beruffe auff alle seine Erbliche Königreich! Es sollen zur Rede kommen/ alle Oesterreichische Erb-Länder/Städt/ Märckt/ und Dorfschafften. Ich will gern/ in der Stille anhören; was/ auß Hoch- und Niderem Standt/ der allgemeine Ruff/ aller insonderheit/ dieser Kayserlichen Geburt- und Wohn-Statt Innwohneren/ bekennen wird. Ist dann jemahlen/ jemand/Gott und der Tugend; dem Glaub/ wie auch Christ-Catholischer Wahrheit/ und Heiligkeit/ auffrichtig/ und vom Hertzen ergeben gewesen; der nicht zugleich auch/ sein Gemüth und Hertz/ von der Kayserlichen/ bishero allein/ über alle/ geprysenen Tugend/ eingenommen zuseyn/ empfunden/ und bekennet hat?» T. WINTER, Drey-mahl-seelige Sanfftmuth [...] Leopoldi I. deß Grossen/ Mild-seeligst- und glorwürdigster Gedächtnu $\beta$ [...], op. cit., p. 52. 157. "Was hat dann jene/ bi $\beta$ in/ fast sterbliche Betrübnu $\beta$ / erbleichte/ und stumme Trauer/ dieser gantzen Staat zuerkennen gegeben? als im 1668. Jahr/ deß verloffenen Weltgangs/ LEOPOLD/ von unversehens empfangenen Gifft/ in augenscheinlich-besorgte Todts-Gefahr gerathen? Es ware ja/ bey 
solcher/ Kindlichen Leyds-Bezeugung/ genugsamb angedeutet: Daß der zusterben damahl begunnende Kayser/villmehr/ wie ein Vatter/ als Herr/ in denen Hertzen der Seinigen/gelebt/ und Geherrschaffet habe? »Id.

158. Winter cite ici Plutarque (Vie d'Agésilas).

159. "Christ-Catholischer Wahrheit/ [...] auffrichtig/ und vom Hertzen ergeben », T. WINTER, Drey-mahlseelige Sanfftmuth [...] Leopoldi I. deß Grossen/ Mild-seeligst- und glorwürdigster Gedächtnuß [...], op. cit., p. 52.

160. «[Der Kayser hat] jede/ die jhn von hier zuweichen inständig bereden wolten/ öfftermahls/ mit diser Antwort/von sich abgewisen : Er seye in Wienn [...] am allersichersten. »Ibid., p. 53.

161. Ibid., p. 54-55.

162. Cf. J. P. SPIELMAN, Leopold I. Zur Macht nicht geboren., op. cit., p. 101-103.

163. Pères de l'Église cités dans la deuxième partie du sermon: SAINT JEAN CHRYSOSTOME, SAINT AMBROISE, SAINT JÉRÔME, THÉODORET DE CYR (exégète et historien, 393 ? - 466 ?), SAINT GRÉGOIRE LE GRAND, SAINT THOMAS D'AQUIN.

164. Auteurs et exégètes modernes cités dans la deuxième partie du sermon : L. DE GRENADE, C. A LAPIDE, G. SANCHEZ, J. VELAZQUEZ.

165. Références et citations tirées de l'Antiquité païenne dans la deuxième partie du sermon : par ordre de fréquence: SÉNÈQUE, De Clementia (huit citations); ovIDE (quatre citations tirées des Amours et des Tristes) ; CICÉRON (quatre citations); JUSTINIEN I ${ }^{\mathrm{ER}}$, empereur byzantin (vers 482-565) : trois citations; CLAUDIEN (370-vers 404) : deux citations poétiques, une citation sur THÉODOSE; TACITE (deux citations), PLUTARQUE (deux citations tirées des Apophtègmes et des Vies des hommes illustres) ; sont en outre cités une fois : PLAUTE (Les Bacchides) ; l'historien romain VALÈrE MAXIME ; TRAJAN; VULCATIUS GALLICANUS, auteur fictif de la biographie de l'usurpateur Avidius Cassius, général de Marc Aurèle ; SEXTUS AURELIUS VICTOR (327-390) : une citation tirée de la biographie de Titus dans le Liber de Caesaribus; PACATUs (panégyrique de THÉODOSE, prononcé en 389) ; LIBANIOS, orateur grec (314-après 393) : discours sur THÉODOSE; THÉODOSE.

166. zONARAS, historien byzantin $\mathrm{du} \mathrm{XI}^{\mathrm{e}}$ siècle ; JUSTE LIPSE (deux citations tirées des Monita et exempla politica, dont la $1^{\text {re }}$ éd. parut en 1605); Aeneas Sylvio PIccolominI (Pie II, 1405-1464); Nicolaus REUSNER (juriste, historien et poète, 1545-1602) ; Laurens BEYERLINCK (jésuite, théologien et encyclopédiste belge, 1578-1627).

167. «Blind und irr-glaubige Heyden ", à propos de Valère Maxime. T. WINTER, Drey-mahl-seelige Sanfftmuth [...] Leopoldi I. deß Grossen/ Mild-seeligst- und glorwürdigster Gedächtnuß [...], op. cit., p. 31.

168. J. BÉRENGER, Histoire de l'empire des Habsbourg, op. cit., p. 404.

169. O. CHALINE, «Ludwig XIV. und Leopold I. als Herrscher. Mythos oder Wirklichkeit des absoluten Fürstentums? », op. cit., p. 37.

170. L. SCHORN-SCHÜTTE, «"Politica christiana" : eine konfessionelle oder christliche Grundordnung für die deutsche Nation?», dans G. Schmidt et E. Müller-Luckner éd., Die deutsche Nation im frühneuzeitlichen Europa: politische Ordnung und kulturelle Identität?, Munich, Oldenbourg, 2010, p. 247 ; cf. également A. MERLE, «Le prince chrétien dans la pensée de Pedro de Ribadeneira et de Juan de Mariana ", dans P. Renoux-Caron et C. Vincent-Cassy éd., Les Jésuites et la Monarchie catholique (1565-1615), Paris, Le Manuscrit, 2012, p. 15-48.

171. O. Chaline, «Ludwig XIV. und Leopold I. als Herrscher. Mythos oder Wirklichkeit des absoluten Fürstentums? », op. cit., p. 38.

172. N. MOUT, « Die politische Theorie in der Bildung der Eliten : die Lipsius-Rezeption in Böhmen und in Ungarn", dans J. Bahlcke, N. Kersken et H.-J. Bömelburg éd., Ständefreiheit und Staatsgestaltung in Ostmitteleuropa : übernationale Gemeinsamkeiten in der politischen Kultur vom 16. 18. Jahrhundert, Leipzig, Universitätsverlag, 1996, p. 245 ; cf. également H. MÜNKLER, «Justus Lipsius », dans H. Münkler, G. Barudio et I. Fetscher éd., Pipers Handbuch der politischen Ideen. Bd. 3 : Neuzeit : von den Konfessionskriegen bis zur Aufklärung, Munich, Piper, 1985, p. 63-67. 
173. Il s'agit de deux citations de ses Monita et exempla politica.

174. "Jener seye in Wahrheit König auch/ ausser allem Zweiffel/ reicher begnadet von Gott; und/ im Reich/ mächtiger/ vortrefflicher/ und vilmehr bekräfftiget; welcher großmüthiger ist/ und stärcker zur Ubertragung aller Schmach- und Unbilden; das ist welcher unbeschwärt/ die/ jhme zugefügte Beleydigungen/ durch Mild- und Sanfftmüthigkeit nachlasset/ und verzeyhet. » J. VELAZQUEZ, dans T. WINTER, Drey-mahl-seelige Sanfftmuth [...] Leopoldi I. deß Grossen/ Mild-seeligst- und glorwürdigster Gedächtnuß [...], op. cit., p. 46.

175. Cf. Friedrich Polleross, « Majesté contre sainteté dans les portraits des Habsbourg au début du XVII ${ }^{\mathrm{e}}$ siècle, dans T. W. Gaehtgens et N. Hochner éd., L'Image du roi de François I ${ }^{e r} \grave{a}$ Louis XIV, Paris, Éd. de la Maison des sciences de l'homme, 2006, p. 33-55.

176. A.-É. SPICA, «Les jésuites et l'emblématique ", Dix-septième siècle, 2007/4 ( $\left.n^{\circ} 237\right)$, p. 646. Cf. également G. Sabatier et P. Vallepin éd., Claude-François Ménestrier: Les jésuites et le monde des images, Grenoble, Presses universitaires de Grenoble, 2009.

177. C.-F. MÉNESTRIER, L'Art des emblèmes, Lyon, Benoist Coral, 1662 ; cité par M.-T. MOUREY, « L'art du ballet de cour aux XVI ${ }^{\mathrm{e}}$ et XVII ${ }^{\mathrm{e}}$ siècles : poétique de l'image animée ", dans La Construction des images : persuasion et rhétorique, création des mythes, Actes en ligne du Colloque École Doctorale IV, "Civilisations, cultures, littératures et sociétés», Paris, 2009; http://www.paris-sorbonne.fr/ IMG/pdf/Colloque_ED_IV_Images_ballet_de_cour_texte_Mourey-1.pdf.

178. A.-É. SPICA, « Les jésuites et l'emblématique », op. cit., p. 646.

\section{AUTEUR}

\section{PHILIPPINE DAUGA-CASAROTTO}

Université Jean Moulin - Lyon 3 